\title{
Phenotypic and Proteomic Characteristics of Human Dental Pulp Derived Mesenchymal Stem Cells from a Natal, an Exfoliated Deciduous, and an Impacted Third Molar Tooth
}

\author{
Gurler Akpinar, ${ }^{1}$ Murat Kasap, ${ }^{1,2}$ Ayca Aksoy, ${ }^{3}$ Gokhan Duruksu, ${ }^{3}$ \\ Gulcin Gacar, ${ }^{3}$ and Erdal Karaoz ${ }^{3,4}$ \\ ${ }^{1}$ DEKART Proteomics Laboratory, Kocaeli University Medical School, Umuttepe, 41380 Kocaeli, Turkey \\ ${ }^{2}$ Department of Medical Biology, Kocaeli University Medical School, Umuttepe, 41380 Kocaeli, Turkey \\ ${ }^{3}$ Department of Stem Cell, Center for Stem Cell and Gene Therapies Research and Practice, Institute of Health Sciences, \\ Umuttepe, 41380 Kocaeli, Turkey \\ ${ }^{4}$ Liv Hospital, Center for Regenerative Medicine and Stem Cell Research \& Manufacturing (Liv MedCell), Besiktas, \\ 34340 Istanbul, Turkey \\ Correspondence should be addressed to Murat Kasap; mkasap2008@gmail.com
}

Received 9 June 2014; Revised 3 September 2014; Accepted 18 September 2014; Published 14 October 2014

Academic Editor: Pavla Jendelova

Copyright (C) 2014 Gurler Akpinar et al. This is an open access article distributed under the Creative Commons Attribution License, which permits unrestricted use, distribution, and reproduction in any medium, provided the original work is properly cited.

\begin{abstract}
The level of heterogeneity among the isolated stem cells makes them less valuable for clinical use. The purpose of this study was to understand the level of heterogeneity among human dental pulp derived mesenchymal stem cells by using basic cell biology and proteomic approaches. The cells were isolated from a natal (NDPSCs), an exfoliated deciduous (stem cells from human exfoliated deciduous (SHED)), and an impacted third molar (DPSCs) tooth of three different donors. All three stem cells displayed similar features related to morphology, proliferation rates, expression of various cell surface markers, and differentiation potentials into adipocytes, osteocytes, and chondrocytes. Furthermore, using 2DE approach coupled with MALDI-TOF/TOF, we have generated a common 2DE profile for all three stem cells. We found that $62.3 \pm 7 \%$ of the protein spots were conserved among the three mesenchymal stem cell lines. Sixty-one of these conserved spots were identified by MALDI-TOF/TOF analysis. Classification of the identified proteins based on biological function revealed that structurally important proteins and proteins that are involved in protein folding machinery are predominantly expressed by all three stem cell lines. Some of these proteins may hold importance in understanding specific properties of human dental pulp derived mesenchymal stem cells.
\end{abstract}

\section{Introduction}

Stem cells are undifferentiated cells that can divide, differentiate, and self-renew to produce new stem cells in multicellular organisms [1]. They can be used in biomedical research, drug discovery, and toxicity testing, as a model in understanding diseases and more importantly for therapeutic purposes in regenerative medicine [2]. To use stem cells successfully in the aforementioned areas, homogenous populations of stem cells have to be isolated, identified, and characterized. However, given the extent of heterogeneity within and among the stem cell lines, the isolation of homogenous stem cell populations appears to be a challenging task [3].
Although there is a descriptive definition for mesenchymal stem cells (MSCs), the extent of heterogeneity within and among MSC lines is overwhelming [4]. This creates a lack of extensive overlap among the studies performed with MSCs. In addition to the genetic background, methods of derivation, growth conditions, the stage of the cell cycle during sample collection, the age and gender of the donor, and the disease status of the donor are the likely factors that contribute to the heterogeneity problem [5]. In general, characterization of MSCs heavily relies on the use of methods such as immunofluorescence microscopy, reverse transcription PCR, and flow cytometry to establish both stem cell identity and function. However, to facilitate stem cell definition 
through cellular phenotypic profile, comparative analysis of gene and protein expression studies should be performed. Currently there is no universally accepted and commonly used cellular phenotypic profile for stem cell characterization. Gene expression profiles are preferred due to their relative ease but they vary greatly with the organisms' state and environment in ways that cannot be easily interpreted. The signature obtained from analysis of the total cell proteome or cell surface proteome ("protein barcodes") is promising and proteomic approaches can be powerful in characterizing the entire protein profile of stem cell phenotype from different niches.

To understand the level of heterogeneity among the MSCs, we isolated MSCs from dental pulps of a natal, an exfoliated deciduous, and an impacted third molar tooth of three different donors. The isolated stem cells were then cultured under the same growth conditions and passaged similarly. The cells were compared on the basis of cellular morphology and expression of MSC specific markers and pluripotent transcription factors. In addition, telomerase activity measurements were performed to collect information about age related changes and cellular senescence. Finally, we compared the protein expression profiles of undifferentiated cells by using 2DE gel electrophoresis followed by MALDITOF/TOF MS/MS analysis. We identified 61 proteins that were predominantly expressed by all three stem cell lines. We believe that some of these proteins may hold importance in understanding specific properties of human dental pulp derived mesenchymal stem cells.

\section{Materials and Methods}

2.1. Isolation and Culture of MSCs from Human Dental Pulps (Natal, Deciduous, and Third Molar). Isolation and culture of human dental pulp derived MSCs were performed according to protocols described elsewhere [6]. Briefly, dental pulps of exfoliated deciduous and impacted third molar teeth were collected by cutting around the cement-enamel junction by using sterilized dental fissure burs to reveal the pulp chamber. The recovery of natal dental pulp is different and harder compared to pulp from adult teeth, where teeth were cut around the cementoenamel junction using dental fissure burs to open the pulp chamber and separate the pulp tissue from the crown and root by an excavator. In the recovery of natal teeth pulp, pliers were used to fracture the dental crown into several parts and the dental pulp was uncovered. The pulp tissue of each sample was gently separated from the crown and root by using sterile excavator and digested with collagenase type I to generate single cell suspensions. MEM-Earle medium containing $15 \%$ fetal bovine serum and $100 \mathrm{IU} / \mathrm{mL}$ penicillin-100 $\mu \mathrm{g} / \mathrm{mL}$ streptomycin was used and the cells were cultured in $25 \mathrm{~cm}^{2}$ plastic tissue culture flasks, incubated at $37^{\circ} \mathrm{C}$ in a humidified atmosphere containing $5 \% \mathrm{CO}_{2}$. The stem cells were isolated on the basis of their ability to adhere to the culture plates. On the third day, red blood and other nonadherent cells were removed and the medium was replaced to allow further growth. The adherent cells grown to $70 \%$ confluency were defined as passage zero $\left(\mathrm{P}_{0}\right)$
TABLE 1: Immunophenotypic characteristics of NDPSCs, SHED, and hDDP-MSCs. The figures in the table are percentages of CD positive cells.

\begin{tabular}{lccc}
\hline Markers & NDPSCs & SHED & DPSCs \\
\hline CD13 & $90.87 \pm 5.24$ & $89.73 \pm 6.76$ & $94.34 \pm 8.42$ \\
CD14 & $0.78 \pm 0.62$ & $0.78 \pm 0.86$ & $0.16 \pm 0.07$ \\
CD29 & $99.43 \pm 0.28$ & $99.88 \pm 0.08$ & $99.44 \pm 0.37$ \\
CD34 & $0.93 \pm 0.62$ & $0.24 \pm 0.08$ & $0.29 \pm 0.24$ \\
CD44 & $98.62 \pm 1.33$ & $99.80 \pm 0.12$ & $99.77 \pm 0.26$ \\
CD45 & $0.65 \pm 0.42$ & $0.28 \pm 0.09$ & $0.12 \pm 0.05$ \\
CD73 & $99.69 \pm 0.36$ & $99.76 \pm 0.36$ & $99.56 \pm 0.14$ \\
CD90 & $97.62 \pm 3.17$ & $99.73 \pm 0.28$ & $99.49 \pm 0.32$ \\
CD106 & $1.04 \pm 0.70$ & $1.18 \pm 0.39$ & $0.14 \pm 0.02$ \\
CD117 & $5.68 \pm 0.24$ & $1.74 \pm 1.72$ & $0.94 \pm 0.85$ \\
CD146 & $81.38 \pm 7.33$ & $57.91 \pm 0.76$ & $54.44 \pm 23.89$ \\
CD166 & $99.15 \pm 0.97$ & $99.51 \pm 0.60$ & $98.59 \pm 0.97$ \\
HLA-ABC & $94.88 \pm 5.25$ & $66.89 \pm 6.36$ & $83.15 \pm 5.65$ \\
HLA-DR & $0.56 \pm 0.39$ & $0.12 \pm 0.02$ & $0.17 \pm 0.05$ \\
\hline
\end{tabular}

cells. Later passages were labeled accordingly. $0.25 \%$ trypsinEDTA solution was used to detach the cells from the plate for passaging and the detached cells were centrifuged at $2000 \times \mathrm{g}$ for 10 minutes, resuspended in one $\mathrm{mL}$ complete medium, counted twice using a Thoma counting chamber, and then plated in $75 \mathrm{~cm}^{2}$ flasks (BD Biosciences, USA) at densities of $1 \times 10^{6}$ cell/flask. Growth medium was replaced every three days over a 10-14-day period.

2.2. Characterization of MSCs by Flow Cytometry. To confirm that MSCs maintain their phenotypic characteristics in vitro, undifferentiated cells were subjected to flow cytometry analyses. After passage three, stem cells were harvested and resuspended in culture medium at a concentration of $10^{6}$ cells $/ \mathrm{mL}$. Flow cytometry was performed by using FACSCalibur (BD Biosciences, USA) according to Karaöz et al. (2010) [6]. The data were analyzed with CellQuest software (BD Biosciences, USA).

Immunophenotyping characterization of MSCs was performed with antibodies against the following human antigens: CD3, CD4, CD13, CD14, CD29, CD34, CD44, CD45, CD73, CD90, CD106, CD117, CD146, CD166, HLA-DR, and HLA-ABC (Table 1). The antigen selection was made based on MSC defining criteria set by Dominici et al. (2006) [7]. All antibodies were from BD Biosciences. More than 50\% staining was regarded as positive.

2.3. In Vitro Stem Cell Differentiation. To induce adipogenic differentiation 3000 cells $/ \mathrm{cm}^{2}$ were seeded onto six-well plates and cultured with Mesencult MSC Basal Medium supplemented with $10 \%$ adipogenic supplement (StemCell Technologies Inc., Canada) and $1 \%$ penicillin/streptomycin for three weeks. The medium was refreshed every two days. Intracellular lipid droplets indicating adipogenic differentiation were confirmed by Oil Red $\mathrm{O}$ staining.

For osteogenic differentiation, 3000 cells $/ \mathrm{cm}^{2}$ were seeded onto collagen (type I) coated cover-slips in six-well 
plates. The differentiation medium was changed twice a week. After four weeks, osteogenic differentiation was assessed by Alizarin Red staining.

To induce chondrogenic differentiation, pelleted micromass of $2.5 \times 10^{5}$ cells was formed by centrifugation at $1300 \times \mathrm{g}$ for 5 minutes and then cultured with chondrogenic medium for two weeks. Medium was changed twice a week. The pellets, fixed with $4 \%$ paraformaldehyde and embedded into paraffin, were stained with Haematoxylin-Eosin and Safranin $\mathrm{O}$ to assess chondrogenic differentiation.

2.4. Measurement of Telomerase Activity. Telomerase activity was measured by conventional telomeric repeat amplification protocol (TRAP) using TeloTAGGG PCR-ELISA kit (Roche Diagnostics, Germany) according to the manufacturer instructions. In brief, after lysis of $2 \times 10^{5}$ cells, three $\mu \mathrm{L}$ of supernatant was incubated with premixed buffer for $20 \mathrm{~min}$ at $25^{\circ} \mathrm{C}$ to show the presumed telomerase activity, and the products were amplified with biotin-labeled primers by PCR. Streptavidin coated ELISA plates were used to quantify the activity by addition of peroxidase specific substrate $\left(3,3^{\prime}, 5,5^{\prime}\right.$ tetramethylbenzidine dihydrochloride; TMB) and reading the optical density at $450 \mathrm{~nm}$. Relative telomerase activity (RTA) was calculated with respect to the control template equivalent to $0.001 \mathrm{~mol} / \mu \mathrm{L}$ DNA.

2.5. Cell Cycle Analysis. Cell cycle was determined with flow cytometry by using BD Cycletest Plus kit (BD Biosciences, USA) following the protocol provided by the manufacturer.

2.6. Protein Extraction and 2DE Gel Electrophoresis. For analysis of proteome profiles, cells were grown in defined media (DMEM, low glucose, pyruvate, Life Tech. Inc., USA). To start cultures, equal number of cells $\left(3 \times 10^{5}\right)$ was seeded into T-75 flasks in triplicate. When $70 \%$ confluency was reached the cells were washed with ample amount of icecold wash buffer (10 mM Tris- $\mathrm{HCl}, \mathrm{pH}$ 7.0, $250 \mathrm{mM}$ sucrose) for three times and removed from the plates by scraping. After $10 \mathrm{~min}$ centrifugation at $4^{\circ} \mathrm{C}$ at $2000 \times \mathrm{g}$, excess wash buffer was decanted and $250 \mu \mathrm{L}$ of cell lysis buffer $2 \mathrm{DE}$ rehydration buffer ( $8 \mathrm{M}$ urea, $2 \mathrm{M}$ thiourea, 4\% CHAPS, $30 \mathrm{mM}$ Tris $\mathrm{pH} 8.5$, and $1 \mathrm{x}$ protease inhibitor cocktail) was added over each cell pellet. To achieve complete lysis, cells were vigorously vortexed for $1 \mathrm{~min}$ in lysis buffer and the supernatant containing the soluble protein fraction was obtained by centrifugation at $20.000 \times \mathrm{g}$ for $30 \mathrm{~min}$ at $4^{\circ} \mathrm{C}$ and stored in lobind tubes (Eppendorf, USA) at $-80^{\circ} \mathrm{C}$ after being snap-frozen in liquid nitrogen. Protein concentration was determined by using modified Lowry assay with the BSA standard (Bio-Rad, USA). $80 \mu \mathrm{g}$ of protein was loaded onto immobilized $\mathrm{pH}$ gradient strips (IPG) $(11 \mathrm{~cm}, \mathrm{pH} 5-8)$ (BioRad, USA) via passive rehydration. Separation based on isoelectric points was performed by using Protean isoelectric focusing cell using the recommended conditions (Bio-Rad, USA). A stepwise incremental voltage program was applied to each strip $(250 \mathrm{~V}$ for $20 \mathrm{~min}$ (linear), $4000 \mathrm{~V}$ for $2 \mathrm{hr}$ (linear), and $10000 \mathrm{~V} / \mathrm{hr}$ (rapid)) by using Protean IEF system (Bio-Rad, USA). The strips were then subjected to a twostep equilibration in equilibration buffers containing $6 \mathrm{M}$ urea, 2\% SDS, 0.375 M Tris $\mathrm{Cl} \mathrm{pH} 8.8,20 \%$ glycerol, and 2\% DTT for the first step and the same buffer without DTT but with iodoacetamide (2.5\%) for the second step. Following isoelectric focusing, strips were subjected to SDS-PAGE. Precast gels (Criterion TGX Any kD, Bio-Rad, USA) were used with Criterion Dodeca gel running system (Bio-Rad, USA) to minimize gel to gel variation. Gels were stained with Colloidal Coomassie stain (KeraFast, USA) and visualized with VersaDoc4000 MP (Bio-Rad, USA). PDQuest Advance (Bio-Rad, USA) 2DE analysis software was used for comparison of protein spot profiles. For automated spot detection, parameters used were sensitivity (13.8), spot size scale (3), and minimum peak intensity (258).

2.7. Image Analysis and Spot Cutting. The outside edges of all of the images were identically cropped by using automated crop tool of PDQuest Advance software (Bio-Rad, USA). Stain speckles were filtered and the standardized areas of interest from all gels were matched and warped and the quantity of each spot was normalized by the total valid spot intensity. Total spot numbers and volumes within the normalized area were determined from the automated analyses. A manual editing tool was used to inspect the determined protein spots detected by the software. Spots that were prone to variation were excluded if they were hard to identify by visual inspection. Every-member matching protein spots were selected among the three mesenchymal stem cells lines. The spots were cut by using automated spot cutting tool, ExQuest spot cutter (Bio-Rad, USA), and disposed into 96well plates for protein identification.

2.8. Identification of Proteins. Protein identification experiments were performed at Kocaeli University DEKART proteomics laboratory (http://kabiproteomics.kocaeli.edu.tr/) by using ABSCIEX MALDI-TOF/TOF 5800 system. In-gel tryptic digestion of the proteins was performed by using an ingel digestion kit following the recommended protocol by the manufacturer (Pierce, USA). Before deposition onto a MALDI plate, all samples were desalted and concentrated with a $10 \mu \mathrm{L} \mathrm{ZipTip}_{\mathrm{C} 18}$ following the recommended protocol (Millipore, USA). Peptides were eluted in a volume of $1 \mu \mathrm{L}$ using a concentrated solution of $\alpha$-CHCA in 50\% acetonitrile and $0.1 \%$ trifluoroacetic acid in water and spotted onto the MALDI target plate. The TOF spectra were recorded in the positive ion reflector mode with a mass range from 400 to $2000 \mathrm{Da}$. Each spectrum was the cumulative average of 200 laser shots. The spectra were calibrated with the trypsin autodigestion ion peaks $m / z$ (842.510 and 2211.1046) as internal standards. Ten of the strongest peaks of the TOF spectra per sample were chosen for MS/MS analysis.

All of the PMFs were searched in the MASCOT version 2.5 (Matrix Science) by using a streamline software, ProteinPilot (ABSCIEX, USA), with the following criteria: National Center for Biotechnology Information nonredundant (NCBInr); species restriction to $H$. sapiens; enzyme of trypsin; at least five independent peptides matched; at most one missed cleavage site; MS tolerance set to $\pm 50 \mathrm{ppm}$ and $\mathrm{MS} / \mathrm{MS}$ tolerance set to $\pm 0.4 \mathrm{Da}$; fixed modification being 
carbamidomethyl (Cys) and variable modification being oxidation (Met); peptide charge of 1+ and being monoisotopic. Only significant hits, as defined by the MASCOT probability analysis $(P<0.05)$, were accepted (see Supplementary Material 1 in Supplementary Material available online at http://dx.doi.org/10.1155/2014/457059).

Classification of proteins was performed by using a freely available classification system PANTHER (http://www.pantherdb.org/) as well as NCBI (http://www .ncbi.nlm.nih.gov/pubmed) and Swiss-Prot/TrEMBL annotations (http://www.expasy.org/) [8].

2.9. Validation of the Selected Proteins by Western Blot Analysis. The same protein preparations from the cells used in the 2DE gel experiments were used for Western blotting (WB) to validate the identified proteins by MALDI-TOF/TOF. Protein extracts (30 $\mu \mathrm{g}$ protein for each lane) were mixed with SDS sample buffer (Laemmli solution) and they were subjected to $12 \%$ SDS-PAGE gels. The gels were transferred onto nitrocellulose membranes $(0.45 \mu \mathrm{m}$, Bio-Rad $)$ at $30 \mathrm{~mA}$ constant current (TurboBlot, Bio-Rad). To prevent nonspecific bindings, the membranes were blocked for $1 \mathrm{~h}$ at room temperature in $5 \%$ nonfat dried milk, 1\% (v/v) Tween 20 in TBS $(50 \mathrm{mM}$ Tris, $150 \mathrm{mM} \mathrm{NaCl}$, adjust $\mathrm{pH}$ with $\mathrm{HCl}$ to $\mathrm{pH}$ 7.6). After blocking, the membranes were incubated overnight at $4^{\circ} \mathrm{C}$ with appropriately diluted polyclonal primary antibodies in TBS-T against Galectin-1 (1:2000, Santa Cruz, sc-28248), DJ1 (1:1000, Abcam, ab-4150), HNRNPH1 (1:10000, Abcam, ab10374), GAPDH (1:2500, Abcam, ab-9485), and monoclonal UCHL-1 (1:5000, Pierce, MAI-46079). GAPDH was used for normalization of each protein sample to ensure equal protein loading. Following three washes with TBS-T, the membranes were incubated with the secondary anti-mouse IgG HRP antibody (Bio-Rad) or anti-rabbit IgG (Bio-Rad) for $1 \mathrm{~h}$ at room temperature. Then the proteins were visualized with an ECL Plus Western blotting detection system (GE Healthcare). The bands were quantitated by using Quantity One $1 \mathrm{D}$ image analysis software (Bio-Rad).

2.10. Statistical Analysis. Flow cytometry, stem cell differentiation and telomerase activity measurements were performed on passage three cells. Any data presented showing the results of a set of analysis were carried out on all cell types. The number of experimental replications, both technical and biological was kept at three.

When it was necessary, statistical analysis of data was carried out by one-way analysis of variance (ANOVA), followed by Tukey's test for multiple comparisons to determine the values that were significantly different. Differences were considered statistically significant at $P<0.05$.

\section{Results}

MSC lines that were isolated and used throughout the study were from three different donors. The NDPSCs were isolated from dental pulp of a tooth that belonged to a female baby who was born with a tooth. The SHED was isolated from dental pulp of a female juvenile who lost one of her deciduous tooth at the age of six and the DPSCs were from a dental pulp of an impacted third molar tooth that belonged to a 27year-old female. All three stem cell lines were characterized to some extent. Morphological analysis of each stem cell line indicated the presence of cells with large, flattened, or fibroblast-like shape (Figure 1(a)). No noteworthy changes in morphology and growth characteristics were observed throughout the passages. Analysis of the common MSC markers with flow cytometry indicated that CD13, CD29, CD44, CD73, CD90, CD146, CD166, and HLA-ABC were expressed by all three stem cell lines (Table 1). Evaluation of proliferation rates by measuring cell viability at various time points indicated that NDPSCs had higher proliferation rate than SHED and DPSCs (Figure 1(b)).

As analyzed by FACS, majority of the stem cells (78\%) were in G1 phase of the cell cycle indicating that the cells were growing in size and synthesizing their mRNA and proteins (Figure 2). The cells that were in S and G2 phases were present in lower ratios $(12 \%$ and $10 \%$, resp.); thus the number of cells undergoing mitotic division was less than the actively growing cells.

Age related telomerase shortening due to loss of telomerase activity is an indicator of stem cell aging [9-11]. We observed a donor-age associated decrease in telomerase activities. The highest telomerase activity was observed with NDPSCs (Figure 3) (considered to be $100 \%$ in relative ratio). There was a $30 \%$ decrease in telomerase activity of SHED in comparison to NDPSCs. The lowest telomerase activity observed was in DPSCs.

Measurement of differentiation potential is required to assess multipotential characteristics of stem cells. Histochemical and immunofluorescence methods were used to demonstrate differentiation potentials of each cell line into adipogenic, osteogenic, and chondrogenic states. During adipogenic differentiation, the lipid droplets enlarged and invaded the entire cytoplasm (Figure 4. (a1), (b1), and (c1)) while during osteogenic differentiation calcium deposits were clearly identified by Alizarin Red staining (Figure 4. (a2), (b2), and (c2)). Chondrogenic differentiation was characterized by the presence of round cells which resembled hyalin chondrocytes. The presence of GAG was shown by Safranin O staining (Figure 4. (a3), (b3), and (c3)). The same staining procedures were performed with the undifferentiated stem cells and were presented as negative staining in Supplementary Figure 2.

A comparative proteomic analysis was performed to identify protein spots that were commonly expressed among the dental pulp derived MSCs. For this purpose stem cells were grown in defined media and protein samples from each MSC type were solubilized and separated by using IPG strips and SDS-PAGE. Following Colloidal Coomassie staining, well resolved and reproducible 2DE gel maps were produced as shown in Figure 5.

An average of $560 \pm 30$ well stained spots per analytical gel were detected when the gels were subjected to automated spot detection and analysis. However, the number of wellresolved spots that matched every member was 183 (Master Gel) with an overall mean coefficient of 60.8 percent. The rest of the spots were either not matchable or not expressed 


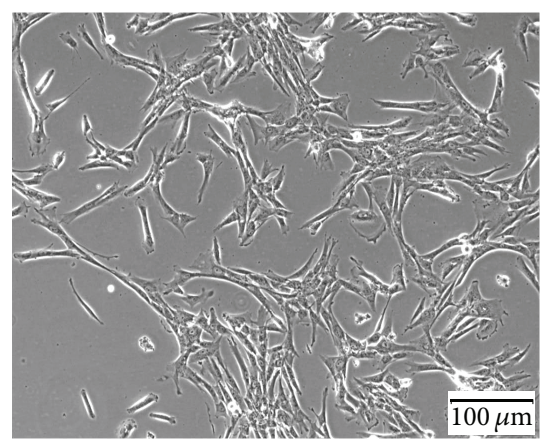

NDPSCs

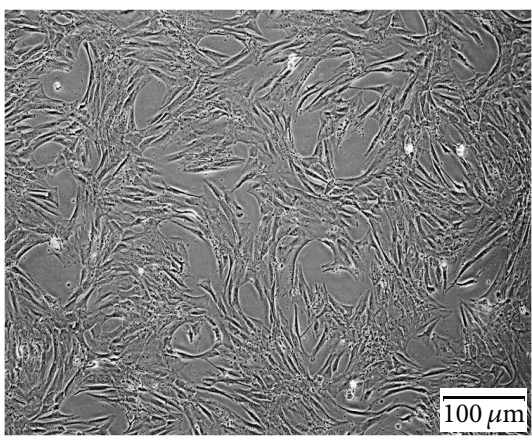

SHED

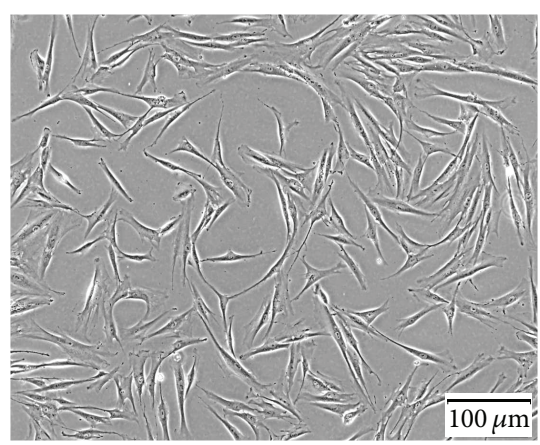

DPSCs

(a)

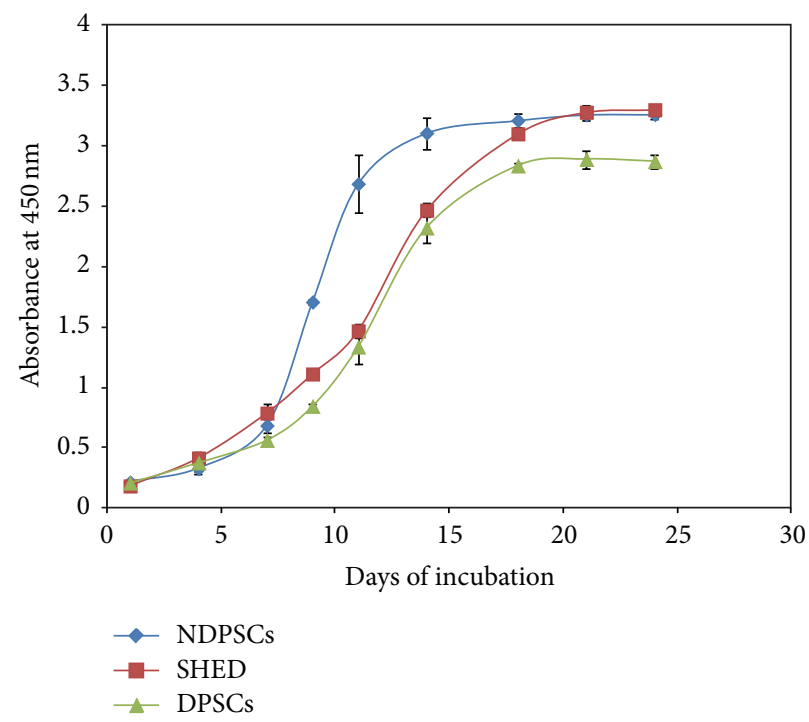

(b)

FIGURE 1: Illustration of MSC morphologies and relevant growth kinetics. (a) Morphology of NDPSCs, SHED, and DPSCs. The cells were at passage three. Images were taken with an inverted microscope (40X). (b) Growth curves for NDPSCs, SHED, and DPSCs over a period of 25 days. The cells were cultured in 96-well plates in triplicate and their growth rates were followed by WST-1 assay, which measures cell viability. DPSCs displayed relatively lower growth rate than SHED and NDPSCs.

by all three stem cell types. By using PDQuest Advance gel analysis software, changes in spot intensities among these 183 matching spots were compared. Spots that were upor downregulated more than 2 -fold were considered to be subjected to regulation (Supplementary Figure 1). We found that $62.3 \pm 7 \%$ of the protein spots were conserved. Ratios for up- and downregulated protein spots were given in Figure 5. In overall, analysis of spot scattering plots and conservation scores indicated that NDPSCs cell proteome was more similar to the SHED proteome than the DPSCs proteome.

To further characterize conserved protein spots, the spots were cut from a preparative gel with an automated spot cutting instrument and subjected to in-gel tryptic digestion followed by MALDI-TOF/TOF analysis. Collectively, 61 protein spots were identified (Table 2). The identified proteins were subjected to analysis based on their molecular function and their involvement in biological processes (Table 3) (Figure 6).
To provide evidence to prove that the results of proteomic analysis were reliable, WB analysis for selected proteins was performed (Figure 7). The results agreed with the proteome analysis indicating that the observed changes in protein spots on $2 \mathrm{DE}$ gels were reliable and real.

Most of the identified proteins were shown to play roles in cellular architecture. Also, proteins that are part of protein folding machinery were described. Some of these proteins are inducible chaperons that are expressed under stress conditions. Transcription, protein biosynthesis, and degradation related proteins that we detected indicated the presence of active cell growth as predicted from cell cycle experiments. Redox metabolism related scavenger proteins that were detected may be an indicator of active cell growth as well. The presence of apoptosis, transcription, protein biosynthesis/ degradation, and energy metabolism related proteins indicated the presence of cellular self-renewal and proliferation. 


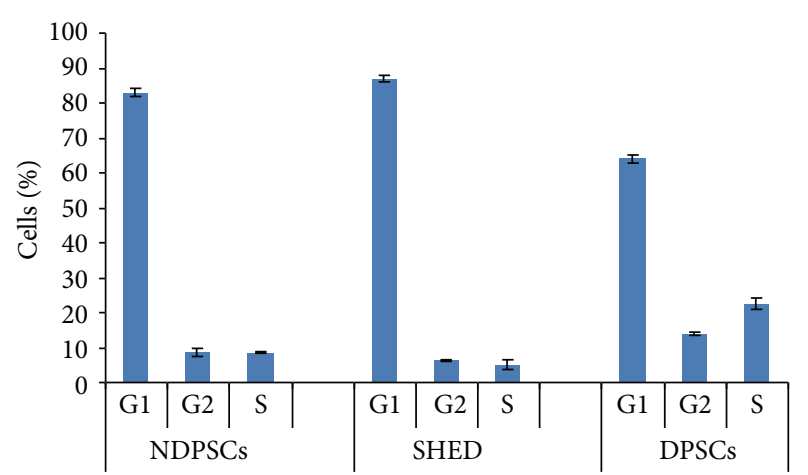

FIgUre 2: Cell cycle analysis of NDPSCs, SHED, and DPSCs. Each sample (10,000 cells) was counted in triplicate by a flow cytometer. The values are expressed as percentage mean \pm standard deviation.

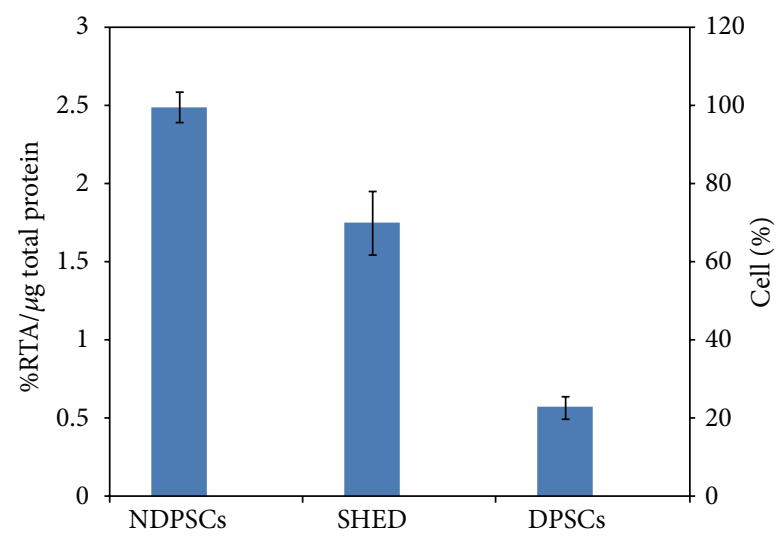

FIgURE 3: Telomerase activities of NDPSCs, SHED, and DPSCs. The activities were measured by conventional telomeric repeat amplification protocol (TRAP) and relative telomerase activities (RTA) were calculated with respect to the control template equivalent to $0.001 \mathrm{~mol} / \mu \mathrm{L}$ DNA.

\section{Discussion}

In the presented study, we attempted to compare multilineage potentials and proteomic profiles of dental pulp derived MSCs isolated from dental pulps of three donors. Our aim was to minimize sample complexity by keeping sample number at three. One might argue that using more material from more donors might produce much more scientifically relevant data. However, increasing the number of donors makes analysis more complicated as each donor has different metabolic status (age, smoking, obesity, metabolic diseases, ethnicity, gender, and undetermined/unknown conditions). Indeed, our initial trials of proteome comparisons using samples from multiple donors generated more variable data and as the number of donors increased in groups the proteome profiles started to deviate more. Therefore, although there are examples in the literature which used samples from multiple donors [12-14], we preferred to use single donor for each group.

The MSCs were compared on the basis of their morphological properties, proliferation rates, expression of common
MSC markers, and in vitro differentiation potentials into adipocytes, osteoblasts, and chondrocytes. Telomerase activities were also measured to monitor the proliferative history of each cell type. Finally, proteome analysis was performed by $2 \mathrm{DE}$ gel electrophoresis with MALDI-TOF/TOF MS/MS to create a protein expression pattern to help with understanding of metabolic pathways that were shared among these MSCs. For proteomic characterization experiments, a better controlled environment was created by using defined media.

In this study, we demonstrated that similarly isolated and grown MSCs from human dental pulp displayed similar morphology, antigenic phenotype, and differentiation potential. These findings do not differ from the previous findings reported by the other studies [12, 15-17]. However, in this study, we demonstrated that similarly isolated and grown MSCs from dental pulps of three different individuals carried considerable variation in their proteomes. A recent study reported similar findings among the proteomes of MSCs isolated from dental tissues (follicle, pulp, and papilla tissue) of a single donor [12]. They reported an average protein spot match ratio of $65 \%$ among the isolated MSCs. We also found low spot conservation scores even though we took an extreme precaution during cell culture and 2DE gel electrophoresis to prevent experimental variations. The precautions included the following. (I) Stem cells from three different dental pulps were isolated by using the same stem cell isolation protocol. (II) Cells were grown in defined growth media under the same growth conditions. (III) Before each passage, cells were allowed to grow to $70 \%$ confluency and equal numbers of cells were used to start new cultures. (IV) To prevent hand to hand variation, the same researchers performed the isolation, growth, and passaging experiments. (V) Protein isolation and $2 \mathrm{DE}$ experiments were also performed by a group of the same researchers. (VI) To prevent gel to gel variations in $2 \mathrm{DE}$ experiments, precast gels were used. They ran and stained under the same conditions by using Criterion gel running and staining systems under appropriate conditions.

Sixty-one of the every-member matching protein spots were identified by MALDI-TOF/TOF MS/MS. The identified proteins were subjected to analysis based on their molecular function and their involvement in biological processes. A total of 10 groups can be formed (Figure 6). Classification of the identified proteins based on molecular function revealed that 11 of the proteins can be grouped as structurally important ones. Among them, actin related protein complex $2 / 3$ regulates tight junctions and function in establishment of branched actin networks [18]. To the best of our knowledge, the existence of this protein has not been described in MSCs. Calponin, a thin filament-associated protein that is implicated in the regulation and modulation of smooth muscle contraction, was also expressed by all our stem cell types. The expression of calponin in human hair follicle derived stem cells and bone marrow derived stem cells was previously reported [19]. Calponin was occasionally used as a marker to characterize smooth muscle cell derived stem cells [20]. Caldesmon is an actin- and myosin-binding protein and cellular component of movement and muscle contraction [21]. There is a strong interaction between caldesmon and calponin [22]. The identification of caldesmon and calponin 


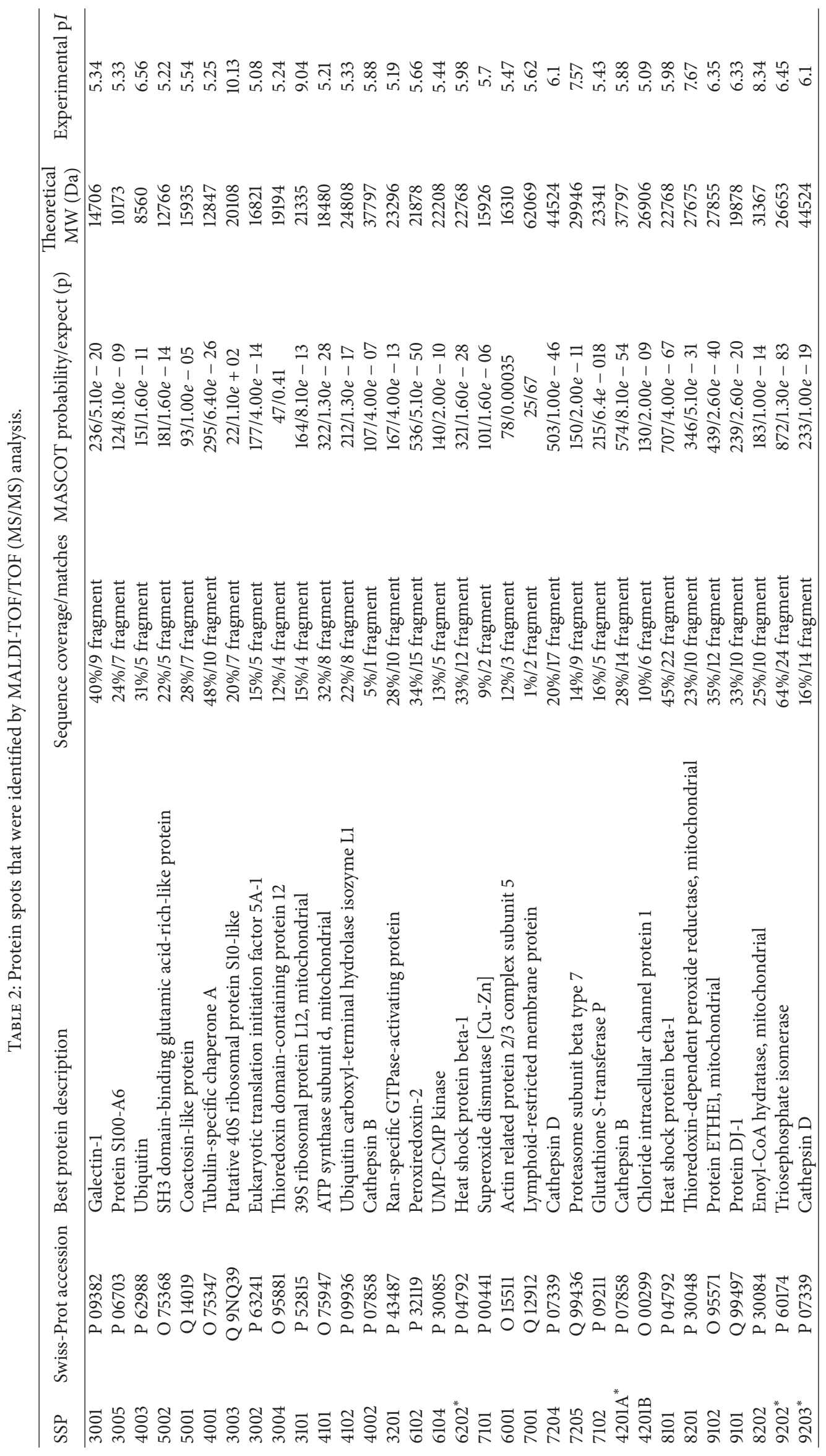




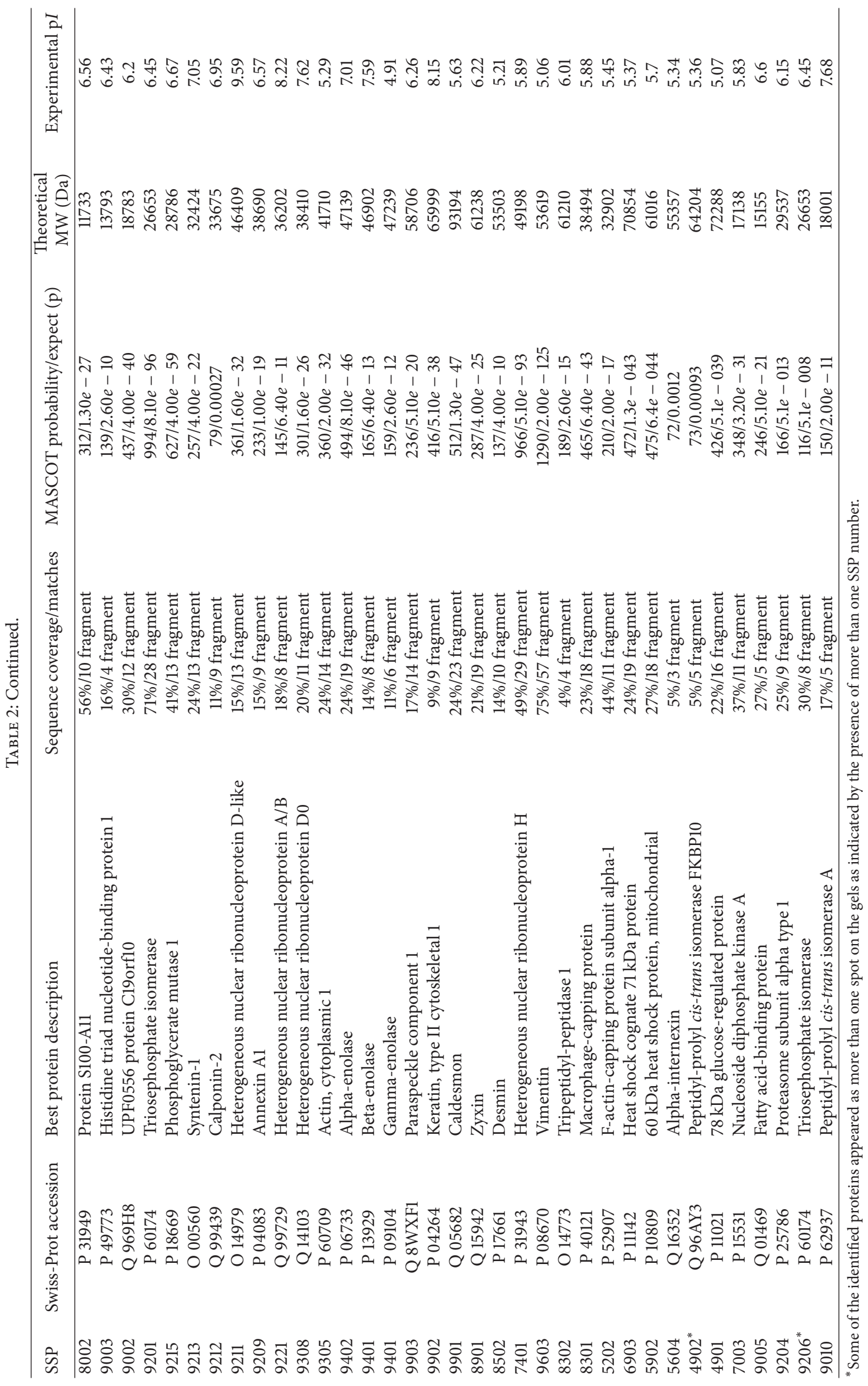




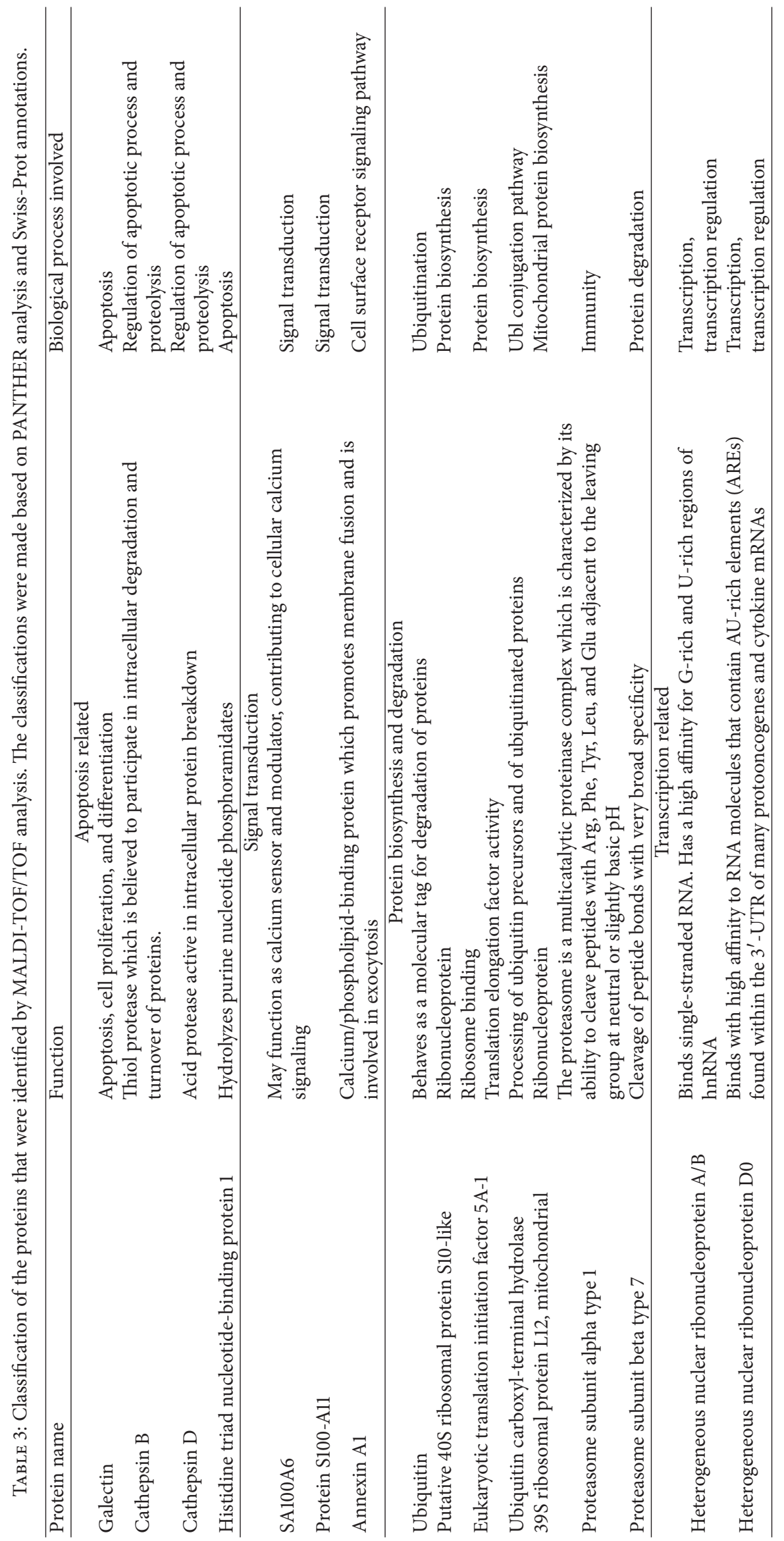




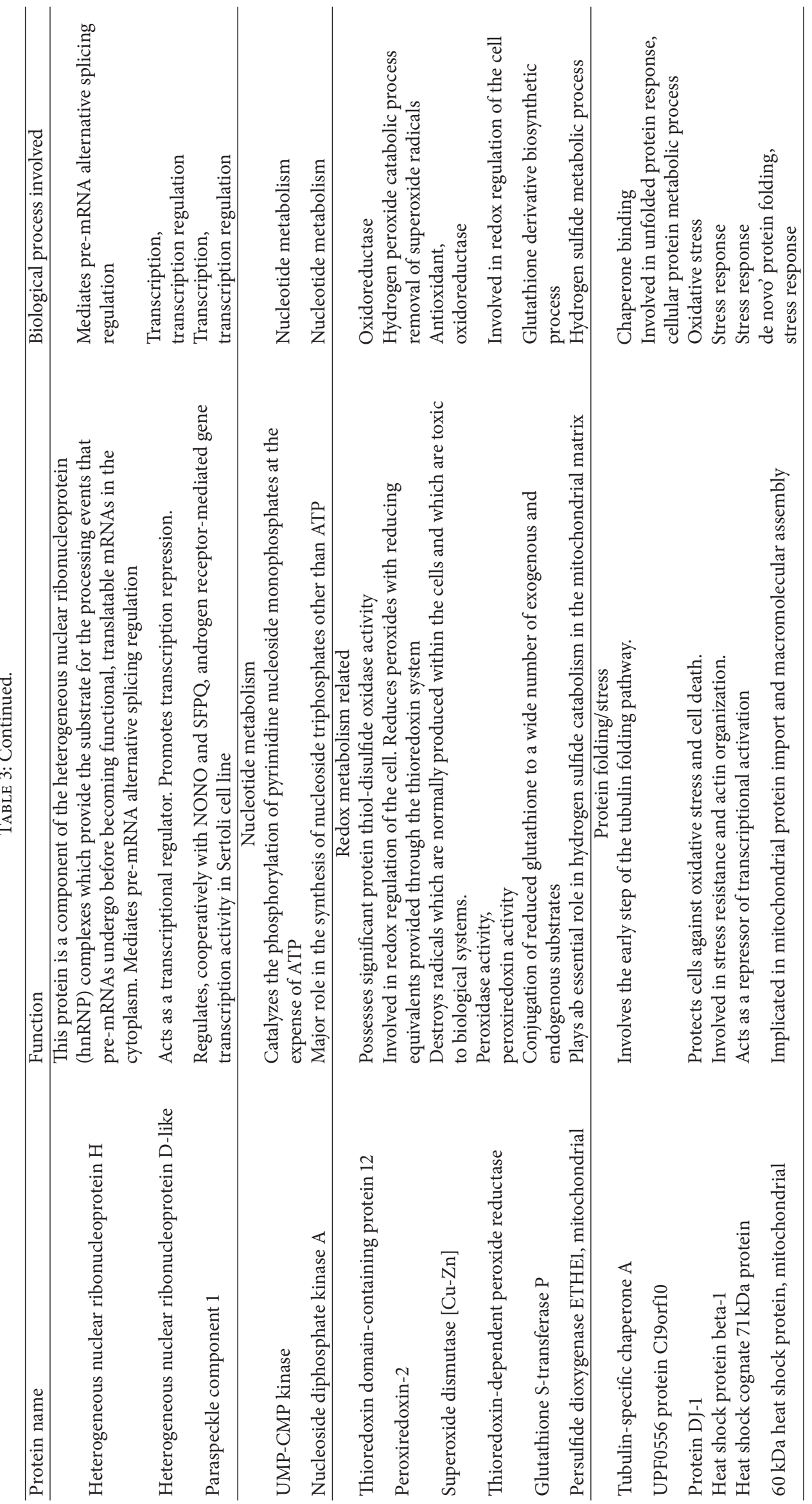




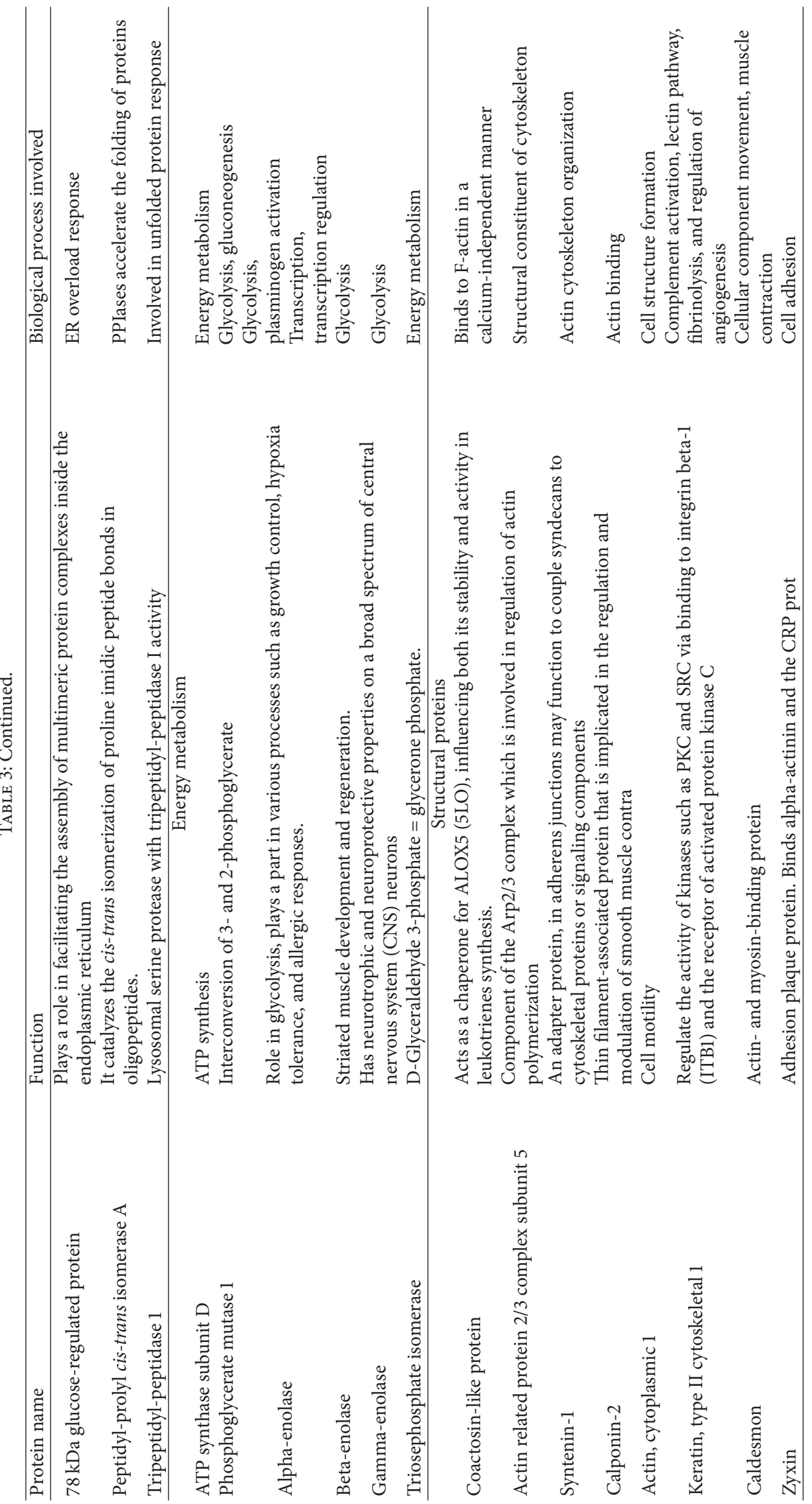




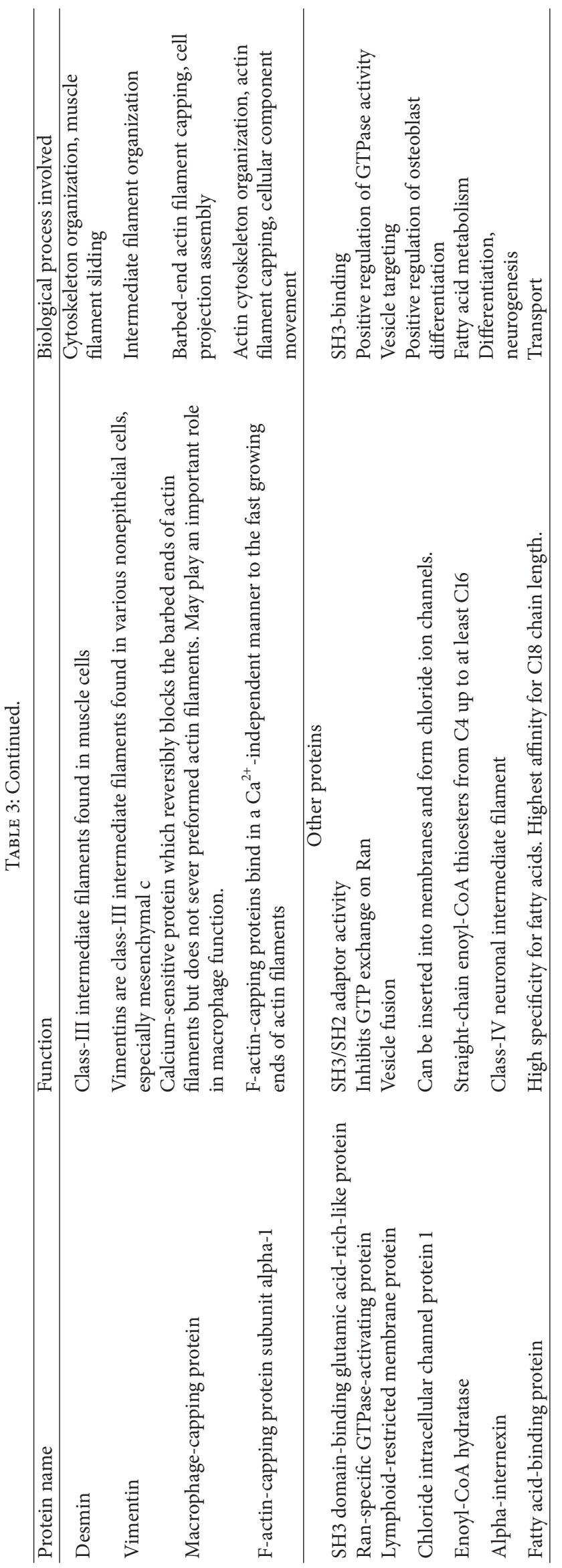




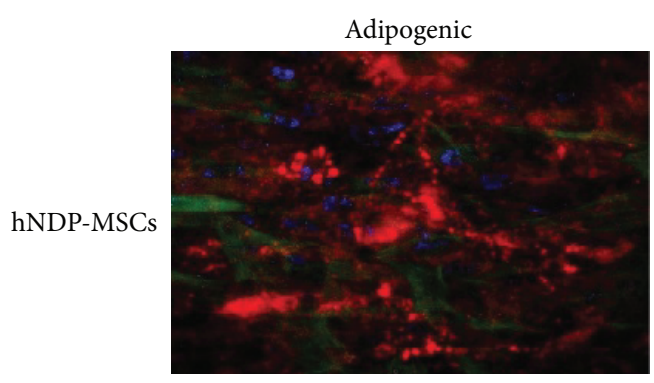

(a1)

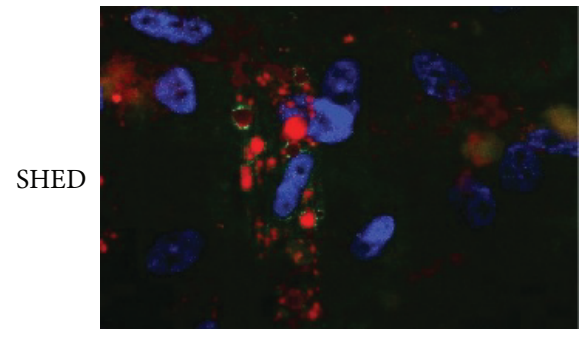

(b1)

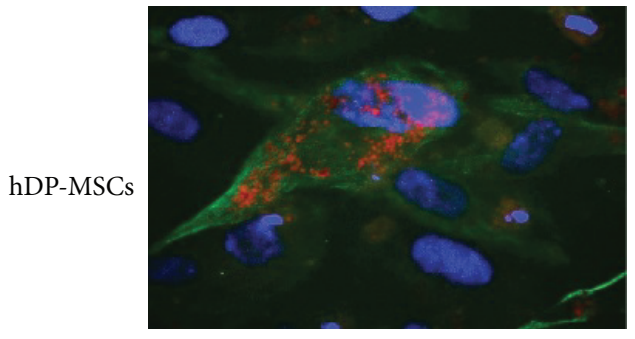

(c1)

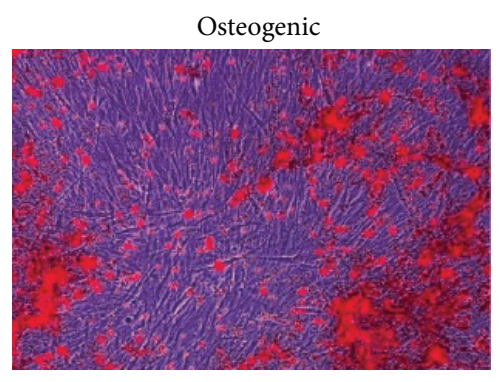

(a2)

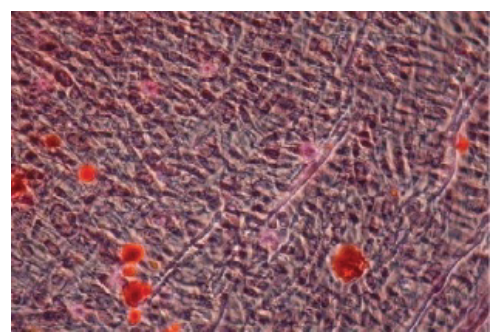

(b2)

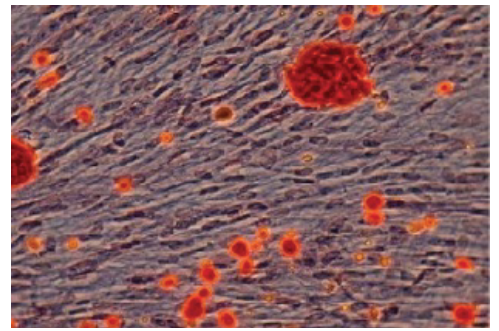

(c2)

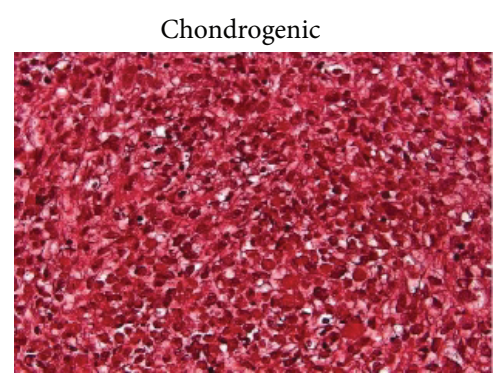

(a3)

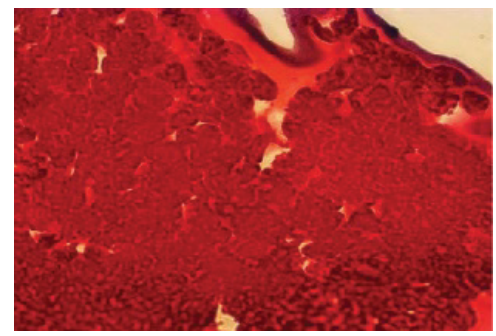

(b3)

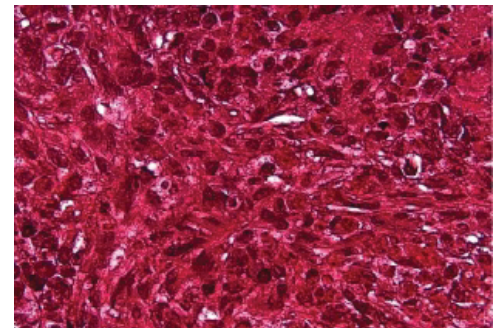

(c3)

FIGURE 4: In vitro differentiation potential of NDPSCs, SHED, and DPSCs. ((a1), (b1), and (c1)). Adipogenic differentiation is visually marked by accumulation of neutral lipid vacuoles in cultures (Oil Red staining). Actin ((a1) and (b1)) and vimentin (c1) expression were shown in green and nuclei in blue with DAPI. ((a2), (b2), and (c2)) Osteogenic differentiation was indicated by the formation of calcified nodule with Alizarin Red S staining. ((a3), (b3), and (c3)) The analyzed sections were positive for Safranin O staining after chondrogenic differentiation.

in our stem cell populations may indicate that certain subpopulations of stem cells in our cultures might be committed to vascular smooth muscle lineage. However, the expression of actin interactin proteins may be due to well known motile nature of MSCs. In addition, expression of caldesmon and annexin $\mathrm{Al}$ is proposed to be a marker for slow growth rate [23]. Because our stem cells were in defined medium their growth rates are expected to be slow and thus they might have expressed these two proteins at a respectable level. Zyxin binds alpha-actinin and the CRP protein and helps cell adhesion [24] and the cells used in this study expressed Zyxin. Zyxin was also determined to be expressed in hMSCs and proposed to be involved in cell to matrix contacts [25]. Previously, coactosin-like protein is shown to be highly expressed in amniotic-fluid derived MSCs [26]. Coactosinlike protein is involved in cytoskeletal organization and movement by binding actin. Both Coactosin-like protein and actin expression were identified in this study.

We have identified five proteins that have roles in redox metabolism and detoxification of the cells. Among them, glutathione S-transferase-P is known to function in detoxification of cells from xenobiotics and decrease susceptibility to cancer. In a previous study, glutathione S-transferase-P is used to distinguish multipotent MSCs isolated from bone marrow [27]. Observation of expression of glutathione Stransferase-P in our stem cells may indicate that our cells did have multipotent MSC properties.

Increased generation of reactive oxygen species (ROS) may be associated with differentiation process. On that line of thought, Clair et al. (1994) demonstrated the expression of MnSOD on cellular differentiation of fibroblasts [28]. They found that MnSOD greatly enhanced fibroblast differentiation into myoblasts. In addition, the protective effect of SOD was demonstrated in bone marrow derived stem cells and in hematopoietic stem cells $[29,30]$. We also detected SOD expression in our stem cells. In addition to SOD, three other proteins that are involved in clearance of ROS were detected in this study. These were peroxiredoxin-2, thioredoxin domain-containing protein 12 , and thioredoxindependent peroxide reductase. Peroxiredoxin reduces peroxides with reducing equivalents provided through the 

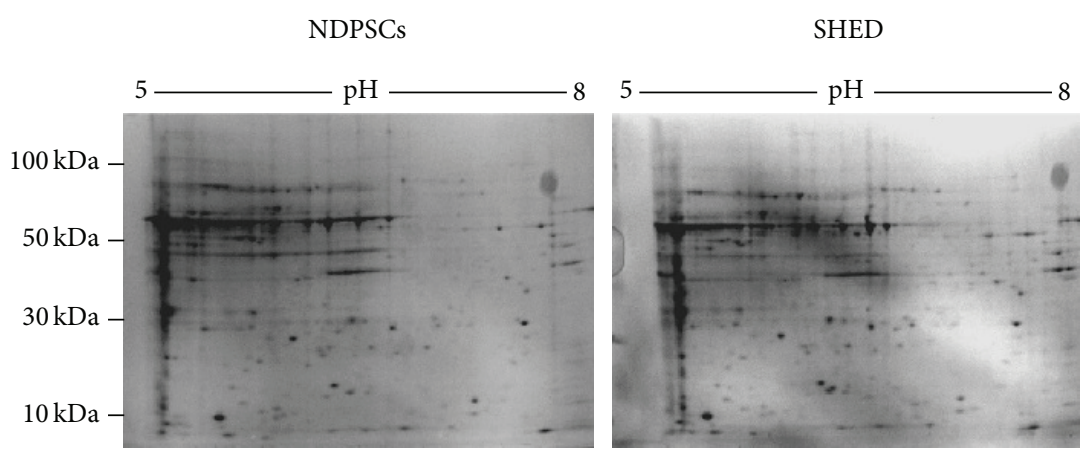

(a)

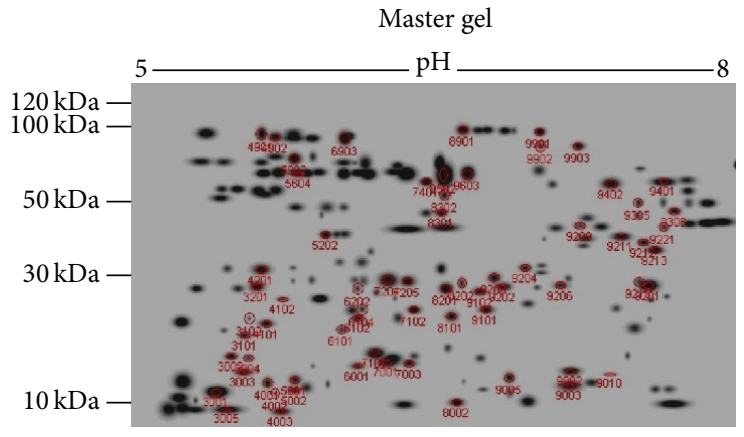

(b)

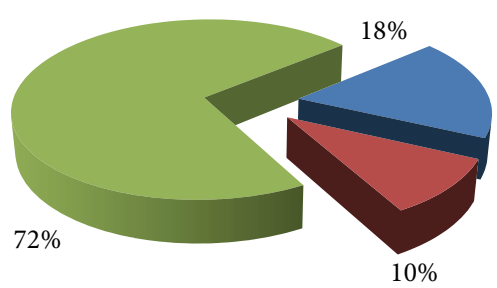

NDPSCs

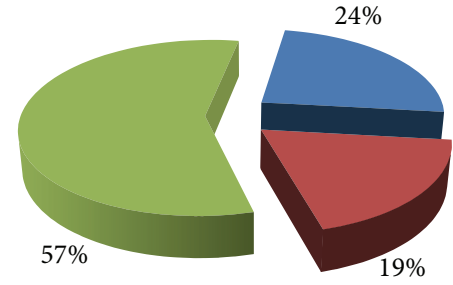

SHED

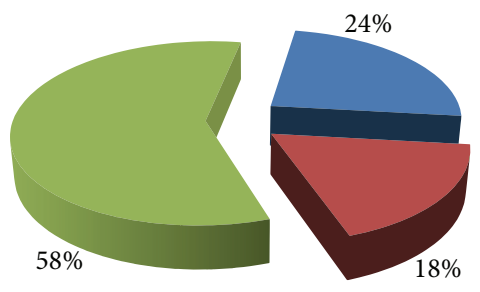

DPSCs

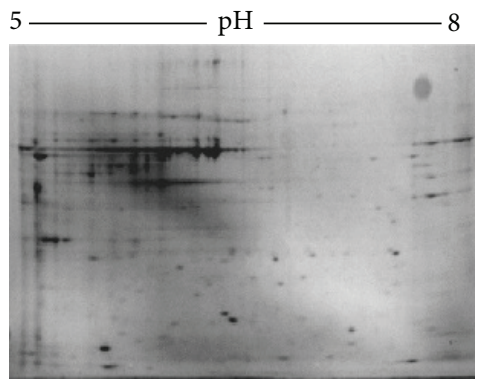

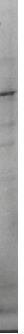

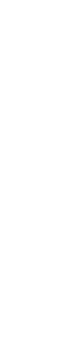




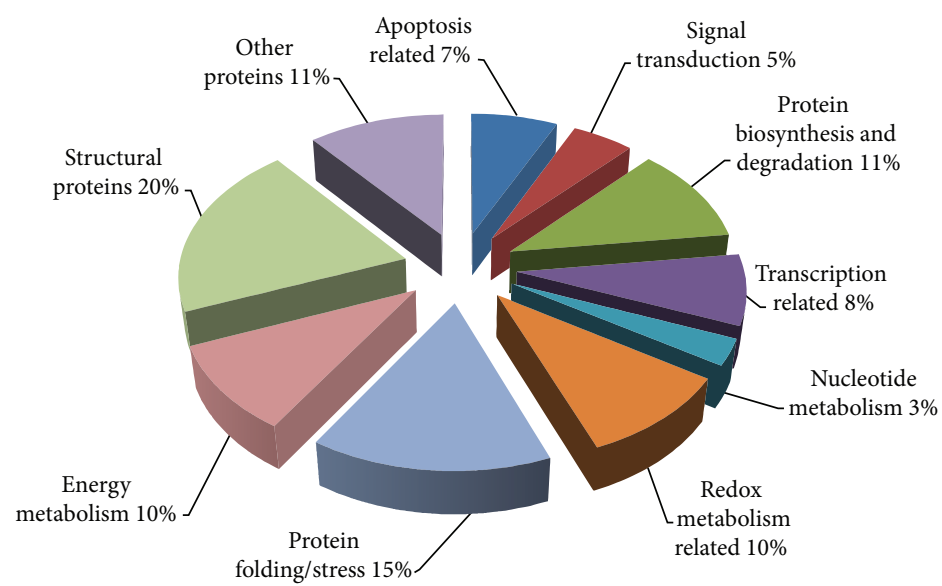

Figure 6: Classification of identified proteins based on their molecular function and their involvement in biological processes. Pie chart representing the distribution of the 61 identified proteins based on their molecular function and biological processes. Assignments were made on the basis of information from PANTHER analysis (http://www.pantherdb.org/) as well as NCBI (http://www.ncbi.nlm.nih.gov/pubmed) and Swiss-Prot/TrEMBL annotations (http://www.expasy.org/).

important modulator of odontogenic and adipogenic differentiation of DPSCs. PIN1 was also shown to promote survival, enhance repair, improve differentiation, and antagonize senescence [35]. PIN1 mRNA and protein levels were upregulated in a time-dependent manner during adipogenic differentiation in human dental pulp derived stem cells [34]. PIN1 may act as an important modulator in human dental pulp derived stem cells and may have significant implications in regenerative medicine. In a study by Nakamura et al. (2012), depression of PIN1 has shown to suppress neuronal differentiation while its overexpression enhanced it [36]. Our group has demonstrated that human dental pulp stem cells display better neural and epithelial stem cell properties [37]. A distinct role for PIN1 has been assigned in induction and maintenance of pluripotency [38]. PIN1 was described to be an indispensable factor for the self-renewal and maintenance of pluripotent stem cells because it can regulate Oct 4 and other substrates via activation of phosphorylation cascades. Therefore, the presence of PIN1 in our stem cells may be related to stemness properties of human dental pulp derived stem cells.

There were four heat shock proteins $(60 \mathrm{kDa}$ heat shock protein, heat shock cognate $71 \mathrm{kDa}$ protein, heat shock protein Beta-1, and $78 \mathrm{kDa}$ glucose-regulated protein) that we identified and they were expressed by all three stem cells. Inducible and constitutive HSP proteins confer synergetic resistance against metabolic changes [39]. Protein DJ-1 is another chaperone protein that protects cells against oxidative stress and cell death. Its role in Parkinson's disease is well known but its significance in stem cell research has not been studied [40]. UPF0556 protein C19orf10 (interleukin-25) is another protein that we detected in our gels. This protein is a secreted protein and is proposed to activate signaling pathways that is involved in unfolded protein response [41]. The last protein that we detected and plays a role in protein folding was tubulin-specific chaperone A which is involved in early steps of the tubulin folding pathway [42]. The presence of chaperons or proteins that play roles in protein folding machinery may indicate the efforts of preservation of stem cell integrity.

We identified several proteins that play roles in transcription and nucleotide metabolism. Among them, PSPC1 is interesting since the functions of paraspeckles in eukaryotic cells are still not known. The presence of a paraspeckle protein (PSP1 alpha) was reported in human embryonic stem cells although the existence of paraspeckles in human embryonic stem cells was reported to occur only upon differentiation [43]. Our cells expressed a paraspeckle component, PSP1C, and this suggested that paraspeckle components are not only expressed by human embryonic stem cells but also expressed by human mesenchymal stem cells and their expression may not require a differentiation process.

Twenty percent of the identified proteins displayed binding activities and five of these proteins are involved in calcium or calcium binding metabolism (protein S100-A6, annexin A1, protein S100-A11, peptidyl-prolyl cis-trans isomerase, and gelsolin). The importance of calcium metabolism has long been recognized in stem cells. In fact, calcium hydroxide is shown to increase recruitment, migration, proliferation, and mineralization of the dental pulp derived MSCs [44]. In a recent study, Chen et al. (2013) demonstrated the effect of S100A4, another calcium binding protein, on proliferation, survival, and differentiation of human osteosarcoma cells [45]. In a more recent study, SA100A6 is proposed to be a novel marker for neural stem cells and may be important for generation of astrocytes in the adult hippocampus [46]. Annexin, which interacts with SA100A6, is required for midbody formation and completion of the terminal phase of cytokinesis and was identified in our study as a part of the calcium binding metabolism.

The presence of four apoptosis related proteins indicated that self-renewal and proliferation of stem cell populations is controlled by induction of apoptosis. Therefore, there is always a balance between the number of actively growing 

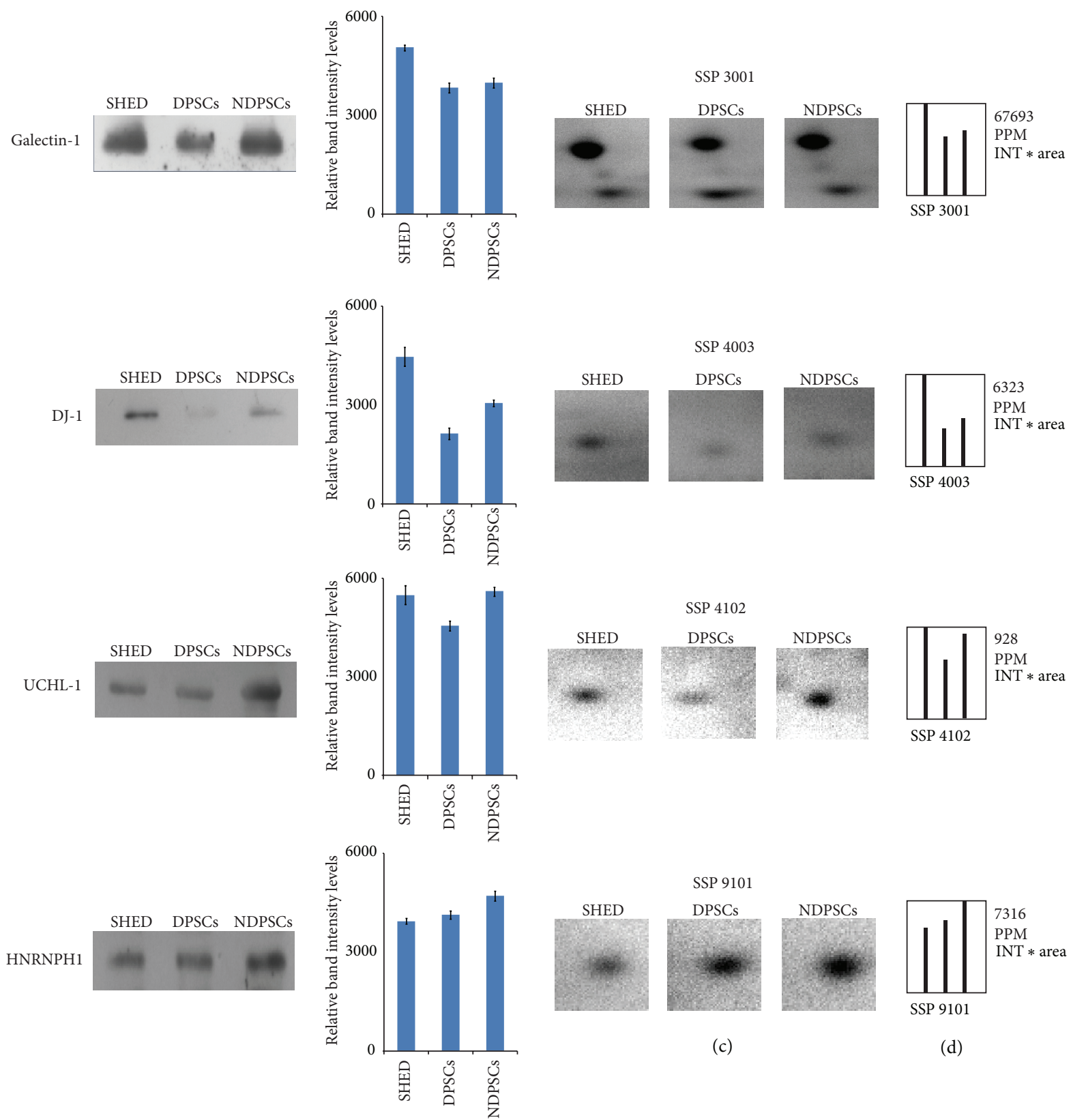

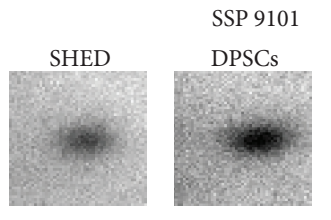

(c)
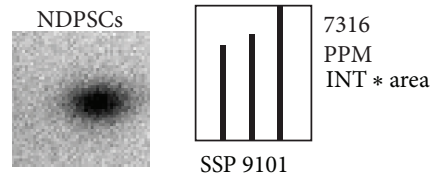

(d)

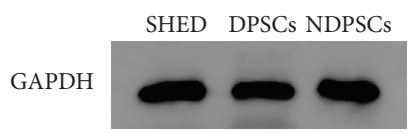

(a)

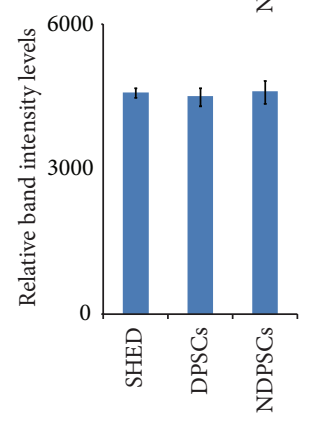

(b)

FIGURE 7: WB validation of the selected proteins identified by MALDI-TOF/TOF analysis. Western blot analysis was used for validation of proteomic results. Conventional 12\% SDS gels were run with whole cell extracts. (a) Three lanes for SHED, DPSCs, and NDP-MSC are shown for each antibody. Galectin-1, DJ-1, UCHL-1, and HNRNPH1 antibodies were used for validation of expressions of the identified proteins. GAPDH was used for the normalization of each protein sample. (b) Relative protein intensities of bands were measured by Quantity One 1D analysis software (Bio-Rad). Each WB was repeated for three times. (c) Representative images of protein spots selected for WB analysis (protein identities corresponding to SSP numbers can be found in Table 2). (d) Comparative intensity graphs of selected protein spots generated by PDQuest Advance software (Bio-Rad). 
stem cells and apoptotic stem cells. In overall, the dynamic nature of stem cell populations is evident by the presence of apoptosis related proteins as well as proteins that are involved in protein biosynthesis/degradation, energy metabolism, and transcription.

\section{Conclusions}

In this study we used basic cell biology and proteomics techniques to uncover the heterogeneity of proteins and their characteristics among three stem cell types. The cells displayed similar features related to morphology, proliferation rates, expression of various cell surface markers, and differentiation potentials. Furthermore, using 2DE with MALDI$\mathrm{TOF} / \mathrm{TOF} \mathrm{MS} / \mathrm{MS}$ approach, we have generated a proteomic profile. We mainly focused on the 61 proteins that were predominantly expressed by all three stem cell types. We are aware that other differentially expressed proteins in each cell type may also be important in understanding specific proteins representing three MSCs from different age groups and those proteins may be a subject of another study. Some of the identified proteins in this study may hold importance in understanding specific properties of human dental pulp derived mesenchymal stem cells. Clarification of the similarities and differences among the proteomes of human dental pulp derived mesenchymal stem cells will help to have a better understanding of these cells and this study is a step taken towards that direction.

\section{Abbreviations}

$\begin{array}{ll}\text { DP: } & \text { Dental pulp derived } \\ \text { hNDP: } & \text { Natal dental pulp derived } \\ \text { SHED: } & \begin{array}{l}\text { Stem cells from human exfoliated } \\ \text { deciduous }\end{array} \\ \text { MSCs: } & \text { Mesenchymal stem cells } \\ \text { MALDI: } & \text { Matrix assisted laser desorption ionization } \\ \text { TOF: } & \text { Time of flight } \\ \text { WB: } & \text { Western blot } \\ \text { EDTA: } & \text { Ethylenediaminetetraacetic acid } \\ \text { TMB: } & 3,3^{\prime}, 5,5^{\prime} \text {-Tetramethylbenzidine } \\ & \text { dihydrochloride } \\ \text { RTA: } & \text { Relative telomerase activity } \\ \text { CHAPS: } & 3-[(3-\text { Cholamidopropyl }) \\ & \text { dimethylammonio]-1-propanesulfonate } \\ \text { DTT: } & \text { Dithiothreitol } \\ \text { IPG: } & \text { Immobilized pH gradient } \\ \text { MS: } & \text { Mass spectrometry } \\ \text { SDS-PAGE: } & \text { Sodium dodecyl sulfate-polyacrylamide } \\ & \text { gel electrophoresis. }\end{array}$

\section{Ethical Approval}

This study was approved by Ethics Committee of Kocaeli University.

\section{Conflict of Interests}

The authors declare that they have no conflict of interests.

\section{Authors' Contributions}

The overall design of the study, including planning, and various aspects of interpretation of results were done by Murat Kasap, Gurler Akpinar, and Erdal Karaoz. Murat Kasap and Gurler Akpinar wrote and revised the paper and designed and carried out the proteomics experiments including MALDITOF/TOFMS/MS analysis. Ayca Aksoy and Erdal Karaoz did all the cell culture experiments. Gokhan Duruksu performed telomerase assay. Gulcin Gacar performed flow cytometer/immunophenotyping and cell cycle analysis.

\section{References}

[1] C. Cookson, "Stem cells: East...and West. Country report: United Kingdom," Scientific American, vol. 293, no. 1, article A23, 2005.

[2] M. Mimeault, R. Hauke, and S. K. Batra, "Stem cells: a revolution in therapeutics-recent advances in stem cell biology and their therapeutic applications in regenerative medicine and cancer therapies," Clinical Pharmacology and Therapeutics, vol. 82, no. 3, pp. 252-264, 2007.

[3] A. D. Ho, W. Wagner, and W. Franke, "Heterogeneity of mesenchymal stromal cell preparations," Cytotherapy, vol. 10, no. 4, pp. 320-330, 2008.

[4] G. C. Parker, M. Anastassova-Kristeva, L. M. Eisenberg et al., "Stem cells: shibboleths of development, part II: toward a functional definition," Stem Cells and Development, vol. 14, no. 5, pp. 463-469, 2005.

[5] W. Wagner, R. E. Feldmann Jr., A. Seckinger et al., "The heterogeneity of human mesenchymal stem cell preparationsevidence from simultaneous analysis of proteomes and transcriptomes," Experimental Hematology, vol. 34, no. 4, pp. 536548, 2006.

[6] E. Karaöz, B. N. Doğan, A. Aksoy et al., "Isolation and in vitro characterisation of dental pulp stem cells from natal teeth," Histochemistry and Cell Biology, vol. 133, no. 1, pp. 95-112, 2010.

[7] M. Dominici, K. le Blanc, I. Mueller et al., "Minimal criteria for defining multipotent mesenchymal stromal cells: the International Society for Cellular Therapy position statement," Cytotherapy, vol. 8, no. 4, pp. 315-317, 2006.

[8] H. Mi, A. Muruganujan, J. T. Casagrande, and P. D. Thomas, "Large-scale gene function analysis with the PANTHER classification system.," Nature protocols, vol. 8, no. 8, pp. 1551-1566, 2013.

[9] I. Flores and M. A. Blasco, "The role of telomeres and telomerase in stem cell aging," FEBS Letters, vol. 584, no. 17, pp. 3826-3830, 2010.

[10] C. Yang, S. Przyborski, M. J. Cooke et al., "A key role for telomerase reverse transcriptase unit in modulating human embryonic stem cell proliferation, cell cycle dynamics, and in vitro differentiation," Stem Cells, vol. 26, no. 4, pp. 850-863, 2008.

[11] E. Hiyama and K. Hiyama, "Telomere and telomerase in stem cells," British Journal of Cancer, vol. 96, no. 7, pp. 1020-1024, 2007.

[12] R. Patil, B. M. Kumar, W.-J. Lee et al., "Multilineage potential and proteomic profiling of human dental stem cells derived from a single donor," Experimental Cell Research, vol. 320, no. 1, pp. 92-107, 2014. 
[13] E. Eleuterio, O. Trubiani, M. Sulpizio et al., "Proteome of human stem cells from periodontal ligament and dental pulp," PLoS ONE, vol. 8, no. 8, Article ID e71101, 2013.

[14] K. M. Mrozik, P. S. Zilm, C. J. Bagley et al., "Proteomic characterization of mesenchymal stem cell-like populations derived from ovine periodontal ligament, dental pulp, and bone marrow: analysis of differentially expressed proteins," Stem Cells and Development, vol. 19, no. 10, pp. 1485-1499, 2010.

[15] R. Hass, C. Kasper, S. Böhm, and R. Jacobs, "Different populations and sources of human mesenchymal stem cells (MSC): a comparison of adult and neonatal tissue-derived MSC," Cell Communication and Signaling, vol. 9, article 12, 2011.

[16] L. Ma, B. Sun, L. Hood, and Q. Tian, "Molecular profiling of stem cells," Clinica Chimica Acta, vol. 378, no. 1-2, pp. 24-32, 2007.

[17] H. Baharvand, A. Fathi, D. van Hoof, and G. H. Salekdeh, "Concise review: trends in stem cell proteomics," Stem Cells, vol. 25, no. 8, pp. 1888-1903, 2007.

[18] K. Zhou, A. Muroyama, J. Underwood et al., "Actin-related protein $2 / 3$ complex regulates tight junctions and terminal differentiation to promote epidermal barrier formation," Proceedings of the National Academy of Sciences of the United States of America, vol. 110, no. 40, pp. E3820-E3829, 2013.

[19] Z. C. Xu, Q. Zhang, and H. Li, "Differentiation of human hair follicle stem cells into endothelial cells induced by vascular endothelial and basic fibroblast growth factors," Molecular Medicine Reports, vol. 9, no. 1, pp. 204-210, 2014.

[20] S. A. Salem, A. N. M. Hwei, A. Saim et al., "Human adipose tissue derived stem cells as a source of smooth muscle cells in the regeneration of muscular layer of urinary bladder wall," Malaysian Journal of Medical Sciences, vol. 20, no. 4, pp. 80-87, 2013.

[21] P. A. J. Huber, C. S. Redwood, N. D. Avent, M. J. A. Tanner, and S. B. Marston, "Identification of functioning regulatory sites and a new myosin binding site in the C-terminal 288 amino acids of caldesmon expressed from a human clone," Journal of Muscle Research and Cell Motility, vol. 14, no. 4, pp. 385-391, 1993.

[22] P. Graceffa, L. P. Adam, and K. G. Morgan, "Strong interaction between caldesmon and calponin," The Journal of Biological Chemistry, vol. 271, no. 48, pp. 30336-30339, 1996.

[23] M. A. Hayat, "Stem cells and cancer stem cells," in Therapeutic Applications in Disease and Injury, K. Tanimoto, Y.-C. Huang, and K. Tanne, Eds., Springer, Berlin, Germany, 2012.

[24] T. Macalma, J. Otte, M. E. Hensler et al., "Molecular characterization of human zyxin," Journal of Biological Chemistry, vol. 271, no. 49, pp. 31470-31478, 1996.

[25] J. K. van Tam, K. Uto, M. Ebara, S. Pagliari, G. Forte, and T. Aoyagi, "Mesenchymal stem cell adhesion but not plasticity is affected by high substrate stiffness," Science and Technology of Advanced Materials, vol. 13, no. 6, Article ID 064205, 2012.

[26] M. G. Roubelakis, K. I. Pappa, V. Bitsika et al., "Molecular and proteomic characterization of human mesenchymal stem cells derived from amniotic fluid: comparison to bone marrow mesenchymal stem cells," Stem Cells and Development, vol. 16, no. 6, pp. 931-951, 2007.

[27] C. Conrad, E. Zeindl-Eberhart, S. Moosmann, P. J. Nelson, C. J. Bruns, and R. Huss, "Alkaline phosphatase, glutathione-Stransferase-P, and cofilin-1 distinguish multipotent mesenchymal stromal cell lines derived from the bone marrow versus peripheral blood," Stem Cells and Development, vol. 17, no. 1, pp. 23-27, 2008.
[28] D. K. St. Clair, T. D. Oberley, K. E. Muse, and W. H. St. Clair, "Expression of manganese superoxide dismutase promotes cellular differentiation," Free Radical Biology and Medicine, vol. 16, no. 2, pp. 275-282, 1994.

[29] A. Petkau, K. Kelly, W. S. Chelack, S. D. Pleskach, C. Barefoot, and B. E. Meeker, "Radioprotection of bone marrow stem cells by superoxide dismutase," Biochemical and Biophysical Research Communications, vol. 67, no. 3, pp. 1167-1174, 1975.

[30] J. Eastgate, J. Moreb, H. S. Nick, K. Suzuki, N. Taniguchi, and J. R. Zucali, "A role for manganese superoxide dismutase in radioprotection of hematopoietic stem cells by interleukin-1," Blood, vol. 81, no. 3, pp. 639-646, 1993.

[31] G. Kasper, L. Mao, S. Geissler et al., "Insights into mesenchymal stem cell aging: involvement of antioxidant defense and actin cytoskeleton," Stem Cells, vol. 27, no. 6, pp. 1288-1297, 2009.

[32] S. Pulavendran, G. Thiyagarajan, and V. Ramakrishnan, "Antioxidant and anti inflammatory action of stem cells in cardiac disease," Journal of Advanced Laboratory Research in Bio$\log y$, vol. 1, no. 2, pp. 71-78, 2010.

[33] K. P. Lu, G. Finn, T. H. Lee, and L. K. Nicholson, "Prolyl cis-trans isomerization as a molecular timer," Nature Chemical Biology, vol. 3, no. 10, pp. 619-629, 2007.

[34] Y. M. Lee, S. Y. Shin, S. S. Jue, I. K. Kwon, E. H. Cho, and E. S. Cho, "The role of PIN1 on odontogenic and adipogenic differentiation in human dental pulp stem cells," Stem Cells and Development, vol. 23, no. 6, pp. 618-630, 2014.

[35] H. Toko, N. Hariharan, M. H. Konstandin et al., "Differential regulation of cellular senescence and differentiation by prolyl isomerase Pinl in cardiac progenitor cells," The Journal of Biological Chemistry, vol. 289, no. 9, pp. 5348-5356, 2014.

[36] K. Nakamura, I. Kosugi, D. Y. Lee et al., "Prolyl isomerase pin1 regulates neuronal differentiation via $\beta$-catenin," Molecular and Cellular Biology, vol. 32, no. 15, pp. 2966-2978, 2012.

[37] E. Karaöz, P. C. Demircan, Ö. Saflam, A. Aksoy, F. Kaymaz, and G. Duruksu, "Human dental pulp stem cells demonstrate better neural and epithelial stem cell properties than bone marrow-derived mesenchymal stem cells," Histochemistry and Cell Biology, vol. 136, no. 4, pp. 455-473, 2011.

[38] M. Nishi, H. Akutsu, S. Masui et al., "A distinct role for pin 1 in the induction and maintenance of pluripotency," The Journal of Biological Chemistry, vol. 286, no. 13, pp. 11593-11603, 2011.

[39] K. Y. Chong, C.-C. Lai, and C.-Y. Su, "Inducible and constitutive HSP70s confer synergistic resistance against metabolic challenges," Biochemical and Biophysical Research Communications, vol. 430, no. 2, pp. 774-779, 2013.

[40] D. W. Miller, R. Ahmad, S. Hague et al., "L166P mutant DJ-1, causative for recessive Parkinson's disease, is degraded through the ubiquitin-proteasome system," Journal of Biological Chemistry, vol. 278, no. 38, pp. 36588-36595, 2003.

[41] T. Weiler, Q. Du, O. Krokhin et al., "The identification and characterization of a novel protein, c19orf10, in the synovium," Arthritis Research and Therapy, vol. 9, article R30, 2007.

[42] A. Guasch, K. Aloria, R. Pérez, J. Avila, J. C. Zabala, and M. Coll, "Three-dimensional structure of human tubulin chaperone cofactor A," Journal of Molecular Biology, vol. 318, no. 4, pp. 1139-1149, 2002.

[43] L. L. Chen and G. G. Carmichael, "Altered nuclear retention of mRNAs containing inverted repeats in human Embryonic stem cells: functional role of a nuclear noncoding RNA," Molecular Cell, vol. 35, no. 4, pp. 467-478, 2009. 
[44] Y.-M. Ji, S. H. Jeon, J.-Y. Park, J.-H. Chung, Y.-H. Choung, and P.-H. Choung, "Dental stem cell therapy with calcium hydroxide in dental pulp capping," Tissue Engineering A, vol. 16, no. 6, pp. 1823-1833, 2010.

[45] X. Chen, G. Luther, W. Zhang et al., "The E-F hand calciumbinding protein s100a 4 regulates the proliferation, survival and differentiation potential of human osteosarcoma cells," Cellular Physiology and Biochemistry, vol. 32, no. 4, pp. 1083-1096, 2013.

[46] J. Yamada and S. Jinno, "S100A6 (calcyclin) is a novel marker of neural stem cells and astrocyte precursors in the subgranular zone of the adult mouse hippocampus," Hippocampus, vol. 24, no. 1, pp. 89-101, 2014. 

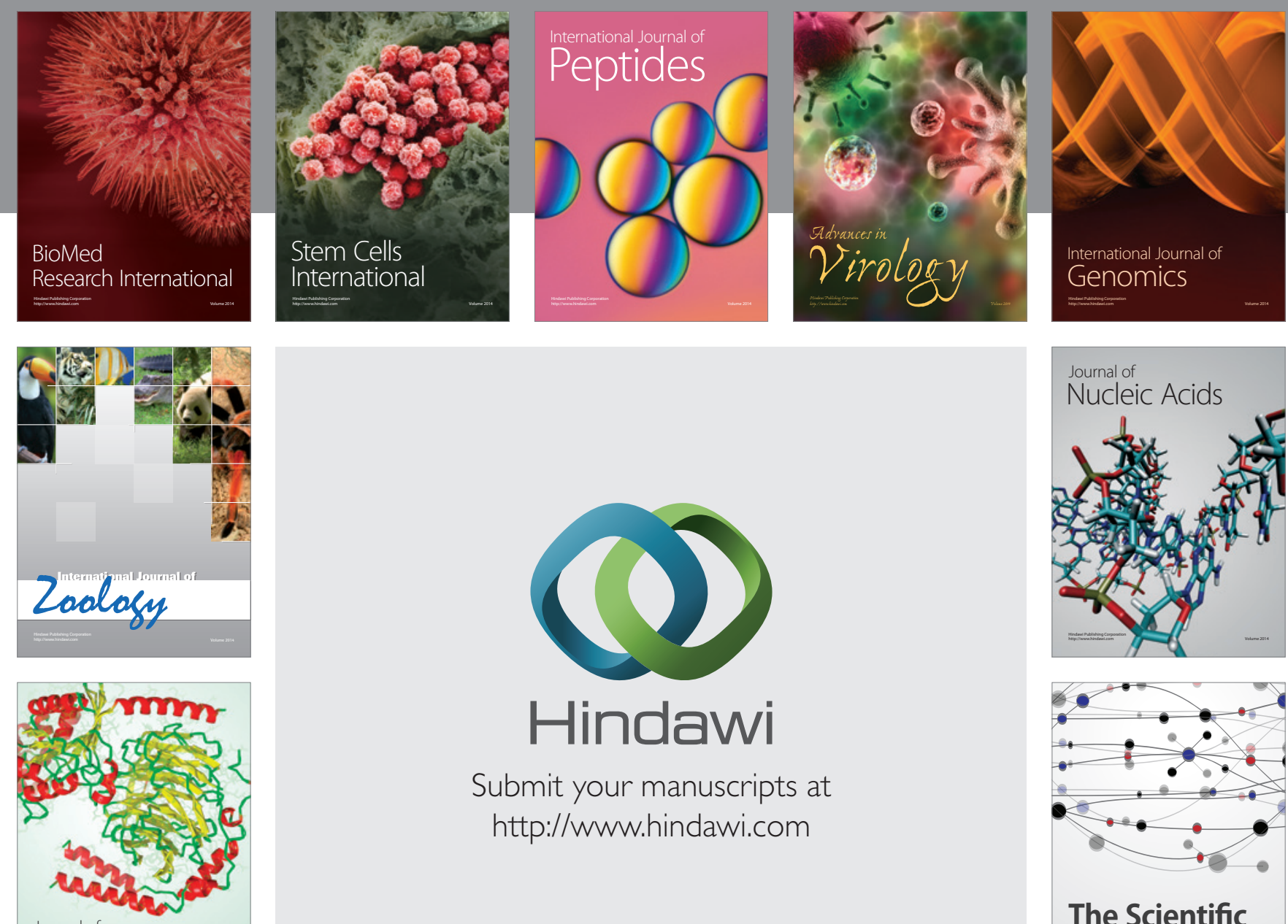

Submit your manuscripts at

http://www.hindawi.com

Journal of
Signal Transduction
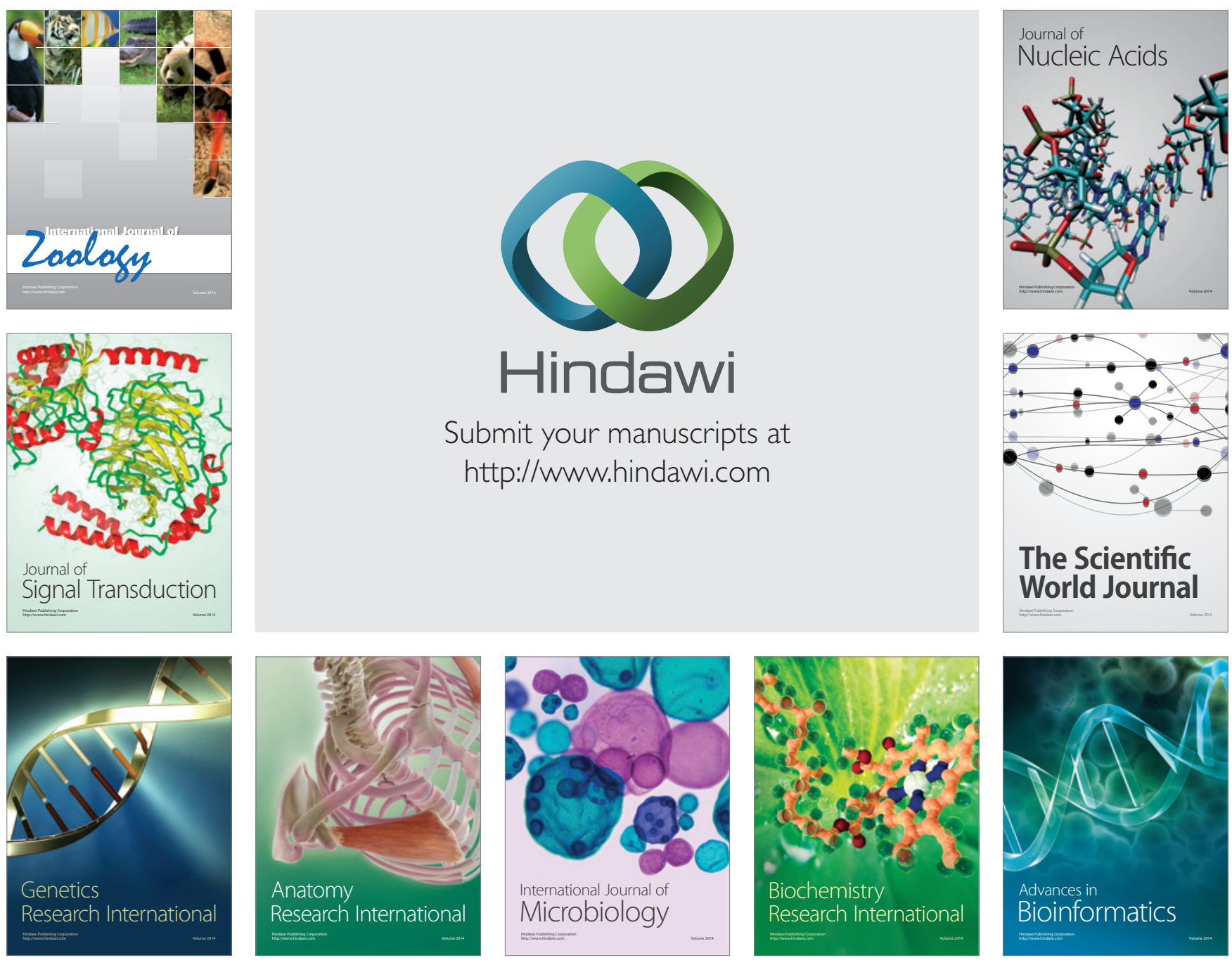

The Scientific World Journal
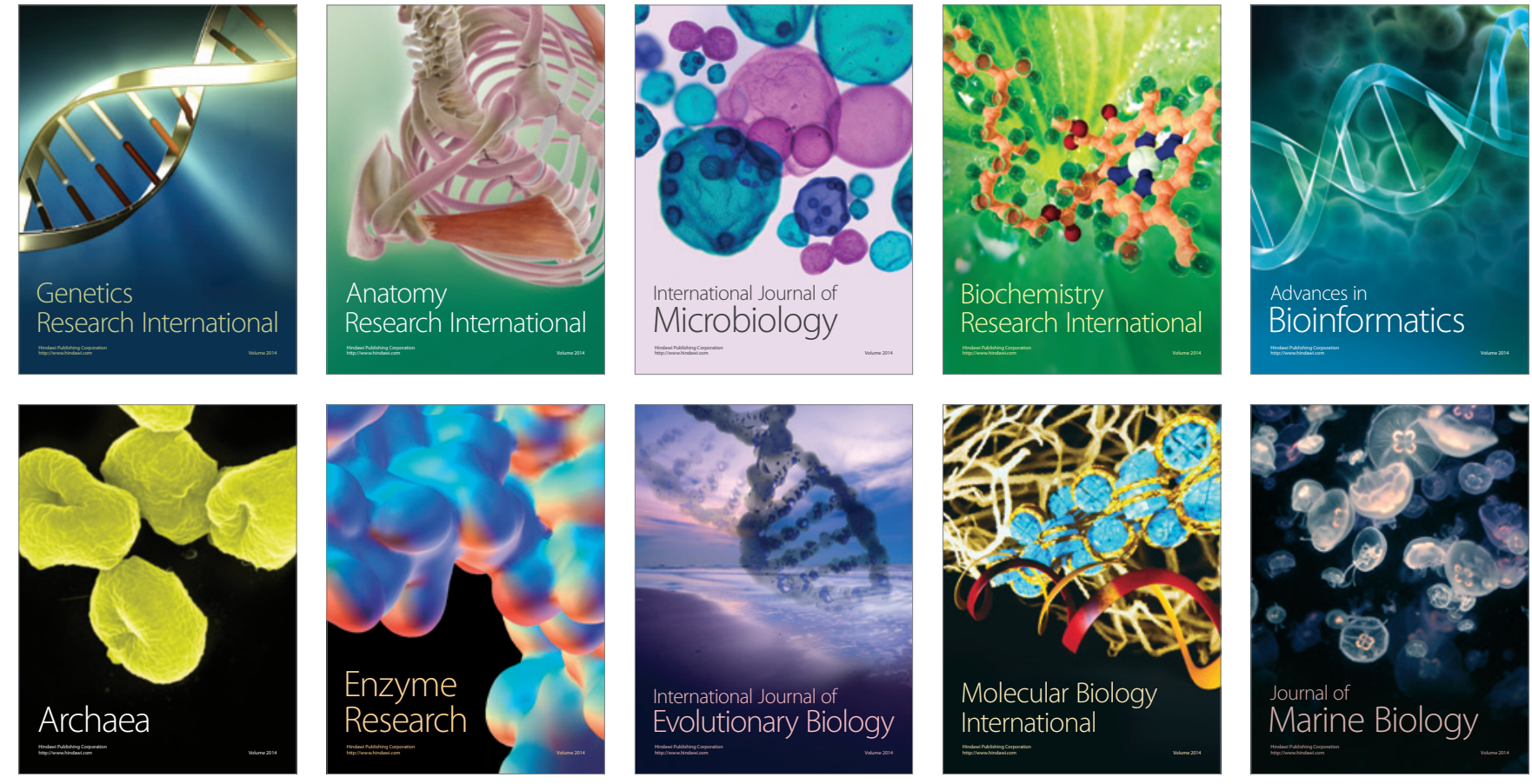